\title{
Systematic genetic interaction studies identify histone demethylase Utx as potential target for ameliorating Huntington's disease
}

\author{
Wan Song ${ }^{1, \dagger, \neq}$, Nóra Zsindely ${ }^{2}$, Anikó Faragó ${ }^{2,3}$, J. Lawrence Marsh $^{1}$ and \\ László Bodai ${ }^{1,2, *, \neq}$ \\ ${ }^{1}$ Department of Developmental and Cell Biology, University of California Irvine, Irvine, CA 92697, USA, \\ ${ }^{2}$ Department of Biochemistry and Molecular Biology and ${ }^{3}$ Doctoral School in Biology, Faculty of Science and \\ Informatics, University of Szeged, 6726 Szeged, Hungary \\ *To whom correspondence should be addressed at: Department of Biochemistry and Molecular Biology, University of Szeged, Közép fasor 52, 6726 Szeged, \\ Hungary. Tel:+3662343951; Fax: +3662544887; Email: bodai@bio.u-szeged.hu
}

\begin{abstract}
Huntington's disease (HD) is a dominantly inherited neurodegenerative disease caused by alterations in the huntingtin gene (htt). Transcriptional dysregulation is an early event in HD progression. Protein acetylation and methylation particularly on histones regulates chromatin structure thereby preventing or facilitating transcription. Although protein acetylation has been found to affect HD symptoms, little is known about the potential role of protein methylation in HD pathology. In recent years, a series of proteins have been described that are responsible for methylating and demethylating histones as well as other proteins. We carried out systematic genetic interaction studies testing lysine and arginine methylases and demethylases in a Drosophila melanogaster HD model. We found that modulating methylation enzymes that typically affect histone positions $\mathrm{H} 3 \mathrm{~K} 4$, H3K36 or H3K79 had varying effects on HD pathology while modulating ones that typically affect constitutive heterochromatin marks at H3K9 and H4K20 generally had limited impact on HD pathology. In contrast, modulating enzymes acting on the facultative heterochromatin mark at H3K27 had specific effects on HD pathology, with reduction of the demethylase Utx rescuing HTT-induced pathology while reducing Polycomb Repressive Complex2 core methylase components led to more aggressive pathology. Further exploration of the mechanism underlying the methylationspecific interactions suggest that these lysine and arginine methylases and demethylases are likely exerting their influence through non-histone targets. These results highlight a novel therapeutic approach for HD in the form of Utx inhibition.
\end{abstract}

\section{Introduction}

Huntington's disease (HD) is a fatal, neurodegenerative disorder caused by a CAG repeat expansion in the Huntingtin (HTT) gene, which encodes an abnormally long polyglutamine (polyQ) repeat in the HTT protein (1). In spite of its monogenic nature, the pathogenesis of HD is complex. Prior studies have identified over 700 proteins interacting with mutant HTT, which are involved in transcription, DNA maintenance, cell cycle regulation, cellular organization, protein transport, energy metabolism, cell signaling, and protein homeostasis (2).

\footnotetext{
${ }^{\dagger}$ Present address: Department of Biology, Indiana University Bloomington, Bloomington, IN 47401, USA.

${ }^{\ddagger}$ These authors contributed equally to this work.

Received: October 26, 2017. Revised: December 12, 2017. Accepted: December 15, 2017

(c) The Author(s) 2017. Published by Oxford University Press. All rights reserved. For Permissions, please email: journals.permissions@oup.com
} 
Multiple studies have noted that altered modification of lysine residues is associated with HD (3-5). This coupled with observed transcription changes in HD has led to the idea that dysregulated lysine modifications might affect pathogenesis by altering histone modifications and thus transcription. Acetylation of histones is a well-known event that affects gene expression by relaxing chromatin structure. Protein methylation occurs on lysine and arginine residues and in many cases affects the same lysine residues as acetylation suggesting a potential interplay between their effects on cellular and pathogenic processes. Consistent with this, several studies have identified altered methylation patterns in HD patients and models (6-8).

However, histones are only one of many substrates targeted by lysine modifying enzymes. Both acetylation and methylation affect a wide-array of proteins (reviewed in 9,10) including histones and non-histone proteins with a wide-variety of functions, including transcriptional regulators, signaling molecules, metabolic enzymes and components of the cytoskeleton. Furthermore, the sets of enzymes participating in the modifications of histones and other proteins are not exclusive but overlapping. For example, the tumor suppressor p53 can be acetylated or methylated at several lysine or arginine residues, to influence its stability and activity (11-13). The lysine methyltransferases Set9 (12) and Set8/PR-Set7 (14) that act on p53 also modify histone H3 at lysine K4 (15) and histone $\mathrm{H} 4$ at lysine K20 (16), respectively. Thus, specific modifying enzymes can affect transcription by modifying both histone and non-histone proteins.

Despite the high number of non-histone acetylation and methylation targets, the majority of studies investigating the role of post-translational modifications (PTMs) on the pathogenesis of HD have focused on the regulation of gene expression by altered modifications of histones. Transcriptional control relies on chromatin structure, which is regulated in part by PTMs of unstructured $\mathrm{N}$-terminal regions of histones that directly change the intrinsic biophysical properties of local chromatin or indirectly allow or prevent docking of effector molecules (17-19). Histone methylation status determines the chromatin environment and thereby regulates transcription (20). Histone methylation marks can be divided into two major categories: active or repressive chromatin marks $(21,22)$ (Table 1). Simplistically, methylated H3K4, H3K36 and H3K79 are associated with actively transcribed genes $(23,24)$, whereas methylated H3K9, H4K20 and H3K27 are usually associated with inactive regions (25). Drosophila melanogaster has single orthologs for most of human histone methylase and demethylase genes and can be an ideal in vivo system to test the role of various histone methylation modifying enzymes on Huntingtin pathology.

In this study, we have sought to identify which methylation modifying loci affect HD pathology by systematically evaluating the effect of identified methyltransferases and demethylases in a Drosophila model of HD. In addition, we have sought to test the assumption of whether the key loci exert their effects by modifying histone residues or whether they exert their effect through other targets of methylation.

\section{Results}

\section{Modulating active chromatin histone methylation marks has varying effects on HD pathology}

We first investigated methyltransferase and demethylase enzymes that act on lysine residues of histone tails whose methylation is associated with active transcription: H3K4, H3K36 or
H3K79. H3K4 methylation represents a specific mark for epigenetic transcriptional activation and tri- and di- methylation on histone $\mathrm{H} 3$ at Lys 4 (H3K4me3/me2) is often found at active genes. H3K4me3 is highly enriched around transcriptional start sites (TSS) (26), while H3K4me2 is present both at TSS and coding regions of transcribed genes (26-31). Di- and tri-methylated forms of $\mathrm{H} 3 \mathrm{~K} 36$ residue are enriched at coding regions of actively transcribed genes and are involved in regulating transcriptional elongation $(26,32)$. H3K79 monomethylation is also enriched in the coding region of active genes, while the dimethylated form can be found on both the TSS and gene body of active genes (26).

In Drosophila, three non-redundant proteins-SET domain containing 1 (Set1), Trithorax (Trx) and Trithorax-related (Trr)-are found in complexes similar to the yeast COMPASS methyltransferase complex that are capable of methylating the H3K4 residues (33). Among these, Set1 was shown to act as the main global H3K4 di- and trimethylase throughout Drosophila development (34).

To determine whether H3K4-specific methyltransferases affect HD pathology, we conducted genetic interaction crosses to test the effects of reduced levels of methyltransferases (either by heterozygous loss of function mutations or by RNAi depletion) on HD phenotypes induced by the neuronal expression of human Httex1p-Q93 transgenes. When expressing mutant Httex1p-Q93 in all neurons with the pan-neuronal elav-GAL4 driver, adult flies exhibit reduced eclosion rates and neuronal degeneration as observed by decreased number of rhabdomeres in ommatidia in the pseudopupil assay (35). RNAi knockdown of Set1 (GD12893) (33) in Httex1p-Q93 expressing flies did not influence viability (1.06 relative eclosion compared to control flies, not significant (N.S.), Fig. 1A) or cause a significant change in the number of rhabdomeres per ommatidium $(+0.02$ rhabdomeres per ommatidium in Htt Set1-RNAi/+ versus $\mathrm{Htt}+/+$ control, N.S., Fig. 1B), indicating that reducing Set1 has no impact on HD pathology.

In contrast, reducing Trx using the hypomorphic trx ${ }^{1}$ allele (36), resulted in significant amelioration of HD pathology in Httex1p-Q93 expressing flies heterozygous for tr $x^{1}$. This was apparent both by a positive change in the number of rhabdomeres per ommatidium $\left(+0.36\right.$ in $\mathrm{Htt} \mathrm{trx}^{1} /+$ versus $\mathrm{Htt}+/+, \mathrm{P}=0.02$, Fig. 1B) and significantly improved viability (relative eclosion of 1.75, $P=0.003$, Fig. $1 \mathrm{~A}$ ), indicating that $\operatorname{Trx}$ inhibition has a positive impact on HD pathology.

Reducing the levels of Trr by heterozygosity of the trr ${ }^{1}$ null allele (37) also rescued the pseudopupil phenotype significantly (+0.91 rhabdomeres per ommatidium in $\mathrm{Htt} \mathrm{trr}^{1} /+$ versus $\mathrm{Htt}+/+$ control, $P=4 \times 10^{-5}$, Fig. 1B), but resulted in reduced viability (0.64 relative eclosion compared to control, $P=0.004$, Fig. $1 \mathrm{~A})$. Similar results were also obtained by reduction of Trr in HD flies by heterozygous $\mathrm{trr}^{3}$ which removes the SET domain (38) (Supplementary Material, Fig. S1A and B). We conclude that unlike the globally acting Set1, reducing the levels of the more specialized H3K4 methylases, Trx and Trr, has a positive impact on Htt-induced neurodegeneration.

Several enzymes are involved in the removal of methyl marks from H3K4 in Drosophila. Among them, Su(var)3-3/dLsd1 (Drosophila ortholog of lysine-specific demethylase 1) specifically demethylates H3K4me2 and H3K4me1 residues $(39,40)$ while Lid (little imaginal discs), the ortholog of the Jarid1 family of Jumonji C (JmjC) domain-containing proteins, demethylates H3K4me3 (41-43). In addition to Su(var)3-3 and Lid, Drosophila Kdm2 (Lysine (K)-specific demethylase 2) has also been shown to possess H3K4me3-specific lysine demethylase activity in adult flies (44). We have previously reported that reducing Lid ameliorates HD pathology (7). Similarly, an RNAi (GD9296) line of Su(var)3-3 
Table 1. A summary of fly methylases and demethylases tested in the study

\begin{tabular}{|c|c|c|c|c|c|}
\hline Site & Function & $\begin{array}{l}\text { Fruit fly protein } \\
\text { /CG number }\end{array}$ & Human homolog & $\begin{array}{l}\text { Effect on reduced } \\
\text { viability }\end{array}$ & $\begin{array}{l}\text { Effect on } \\
\text { neurodegeneration }\end{array}$ \\
\hline \multicolumn{6}{|c|}{ Lysine methyltransferases and demethylases } \\
\hline \multirow[t]{6}{*}{$\mathrm{H} 3 \mathrm{~K} 4$} & Methylation & Set1/CG40351 & SETD1A, SETD1B & NS & NS \\
\hline & & $\operatorname{Trx} / C G 8651$ & MLL1/2 & $\mathrm{Su}$ & $\mathrm{Su}$ \\
\hline & & Trr/CG3848 & MLL3/4 & E/NS & $\mathrm{Su} / \mathrm{Su}$ \\
\hline & Demethylation & $\mathrm{Su}($ var)3-3/CG17149 & LSD1 & $\mathrm{Su}$ & $\mathrm{Su}$ \\
\hline & & Kdm2/CG11033* & KDM2B & $\mathrm{Su}$ & $\mathrm{Su}$ \\
\hline & & Lid/CG9088 & JARID1 & - & - \\
\hline \multirow[t]{6}{*}{ H3K9 } & Methylation & Egg/CG12196 & ESET & NS/NS & NS/NS \\
\hline & & Su(var)3-9/CG43664 & SUV38H & $\mathrm{E} / \mathrm{Su}$ & NS/NS \\
\hline & & G9a/CG2995 & G9a & NS/E & NS/NS \\
\hline & Demethylation & JHDM2/CG8165 & JHDM2 & $\mathrm{Su}$ & NS \\
\hline & & Kdm4B/CG33182* & JMJD2 & NS & NS \\
\hline & & Kdm4A/CG15835* & JMJD2 & $\mathrm{Su}$ & NS \\
\hline \multirow[t]{2}{*}{ H3K27 } & Methylation & $\mathrm{E}(\mathrm{z}) / \mathrm{CG} 6502$ & Ezh2 & $\mathrm{E} / \mathrm{E}$ & $\mathrm{E} / \mathrm{E}$ \\
\hline & Demethylation & Utx/CG5640 & UTX/UTY, JMJD3 & $\mathrm{NS} / \mathrm{NS}$ & $\mathrm{Su} / \mathrm{Su}$ \\
\hline \multirow[t]{6}{*}{ H3K36 } & Methylation & Set2/CG1716 & SET2 & NS & $\mathrm{Su}$ \\
\hline & & Ash1/CG8887 & ASH1 & $E$ & $\mathrm{E}$ \\
\hline & & NSD/CG4976 & NSD1 & - & - \\
\hline & Demethylation & Kdm4A/CG15835* & JMJD2 & $\mathrm{Su}$ & NS \\
\hline & & Kdm2/CG11033* & JHDM1A/1B & $\mathrm{Su}$ & $\mathrm{Su}$ \\
\hline & & Kdm4B/CG33182* & JMJD2 & NS & NS \\
\hline H3K79 & Methylation & Gpp/Cg42803 & DOT1L & NS/NS & $E / E$ \\
\hline \multirow[t]{2}{*}{$\mathrm{H} 4 \mathrm{~K} 2 \mathrm{O}$} & Methylation & PR-Set7/CG3307 & SET8 & NS & NS \\
\hline & & Hmt4-20/CG13363 & SUV420H & NS & NS \\
\hline \multicolumn{6}{|c|}{ Protein arginine methyltransferases } \\
\hline Unknown & Methylation & Art3/CG6563 & PRMT3 & $\mathrm{NS} / \mathrm{Su}$ & NS/NS \\
\hline Unknown & Methylation & FBXO11/CG9461 & PRMT9/FBXO11 & $\mathrm{NS} / \mathrm{Su}$ & NS/NS \\
\hline
\end{tabular}

The known histone site targets, CG numbers and human homologs are listed, and the summary of the observed effects of partial loss of the enzymes on mutant Huntingtin-induced reduced viability and neurodegeneration are shown. NS, no significant change; E, enhancement; Su, suppression; -, not tested; ${ }^{\mathrm{m}}$ marks enzymes with activities toward several histone lysine residues. Results gained with tests using independent alleles are separated by /.

rescued the pseudopupil phenotype ( +0.32 rhabdomeres per ommatidium in $\mathrm{Htt} \mathrm{Su}$ (var)3-3-RNAi versus $\mathrm{Htt}+/+, \mathrm{P}=0.03$, Fig. 1B) and viability (1.54 relative eclosion, $P=0.0001$, Fig. $1 \mathrm{~A}$ ). Heterozygous loss of $\mathrm{Kdm} 2$ by the amorphic $\mathrm{Kdm} 2^{\mathrm{DG} 12810}$ allele (45) has also ameliorated neurodegeneration $(+0.66$ rhabdomeres

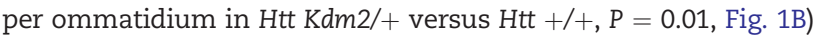
and improved viability (1.94 relative eclosion, $\mathrm{P}=2 \times 10^{-7}$, Fig. 1A). Thus, reduction of H3K4 demethylases can have a positive impact on HD pathology.

Next we investigated the effects of modulating H3K36 methylation status on HD pathology. In Drosophila, H3K36 trimethylation is catalyzed by the product of the Set domain containing 2 gene (Set2, dHypb) and dimethylation is mediated by the product of the absent, small or homeotic discs 1 gene (Ash1) (46) and Mesoderm-expressed 4 gene (Mes4) (47). We tested an RNAi line of Set2 (B24108) that was shown to eliminate H3K36 methylation in larvae (48). We saw significant rescue of HTT-induced neurodegeneration when Set2 was downregulated $(+0.51$ rhabdomeres per ommatidium in $\mathrm{Htt}$ Set2-RNAi/ + versus $\mathrm{Htt}+/+, P=0.02$, Fig. 1D) while no significant change in viability was observed (relative eclosion of 1.23, N.S., Fig. 1C).

The methyltransferase activity of Ash1 was initially reported to be directed towards H3K4, H3K9 and H4K20 $(49,50)$; however, recent evidence supports its dimethylation activity specifically towards H3K36 in vitro $(46)$ and in vivo $(51,52)$. In contrast to the positive effect from reducing Set2, heterozygosity of $a \operatorname{sh} 1^{22}$, a null allele (53), resulted in an enhancement of HD pathology in Httex1p-Q93 expressing flies, apparent in both significantly more neurodegeneration $(-0.75$ rhabdomeres per ommatidium in $\mathrm{Htt} a \operatorname{ash} 1^{22} /+$ versus $\mathrm{Htt}+/+, \mathrm{P}=0.0002$, Fig. $\left.1 \mathrm{D}\right)$ and a $50 \%$ reduction in relative eclosion rate $(0.51, P=0.0001$, Fig. $1 C)$.

Demethylation of histone H3K36me3/me2 (and H3K9me3/ me2) is mediated by the KDM4 subfamily, which belongs to a large family of JmjC domain-containing proteins $(22,43,54)$. In Drosophila, $\mathrm{Kdm} 4 \mathrm{~A}$ is capable of demethylating H3K36me2 and H3K36me3 and regulates H3K36 methylation at multiple euchromatic sites $(43,55)$. To test the influence of $\mathrm{Kdm} 4 \mathrm{~A}$ on $\mathrm{HD}$ pathology we used the Kdm4A $\mathrm{A}^{\mathrm{KG} 04636}$ allele in which a P element inserted in the coding region of $\mathrm{Kdm} 4 \mathrm{~A}$ abrogates its expression (55). Reduced levels of $\mathrm{Kdm} 4 \mathrm{~A}$ (i.e. Htt-expressing flies that are also heterozygous for $\mathrm{Kdm} 4 \mathrm{~A}^{\mathrm{KG} 04636}$ ) led to significantly increased viability ( 1.45 relative eclosion, $P=0.004$, Fig. 1 C) but had no effect on neurodegeneration $(+0.10$ change of rhabdomeres per ommatidium, N.S., Fig. 1D).

The grappa gene (gpp) is solely responsible for catalyzing the mono-, di- and tri- methylation of $\operatorname{H3K} 79(56,57)$ and has the unusual property of exhibiting phenotypes and genetic interactions that are characteristic of both Polycomb-group (PC-G) and Trithorax-group (TRX-G) genes (56). We tested two X-ray-induced loss of function alleles of $g p p, g p p^{\mathrm{X}}$ and $g p p^{\mathrm{XXV}}$. Heterozygous reduction of Gpp in Htt-expressing flies resulted in modest, yet significant increase in neurodegeneration $(-0.23$ rhabdomeres per ommatidium in $\mathrm{Htt} g \mathrm{pp}^{\mathrm{x}} /+$ versus $\mathrm{Htt}+/+$ control, $P=0.01$, Fig. 1F) with no significant impact on viability (relative eclosion of 1.31, N.S., Fig. 1E). Reducing Gpp by the other loss of function allele, $g p p^{\mathrm{XXV}}$, gave similar results with 
A

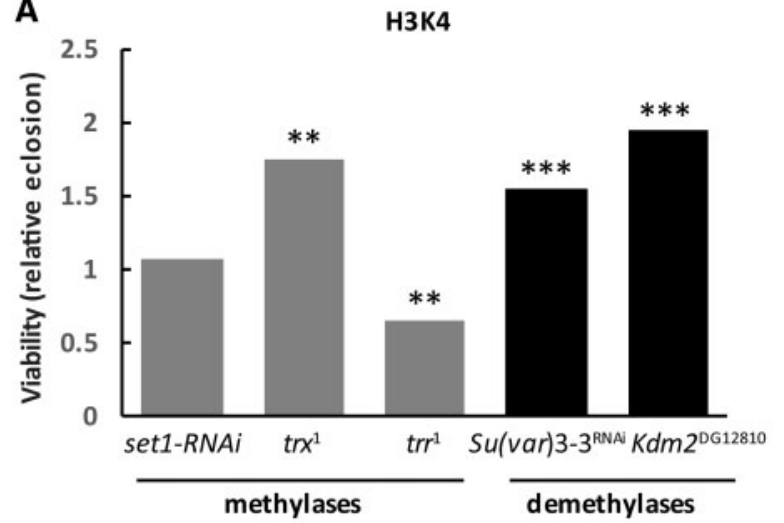

C

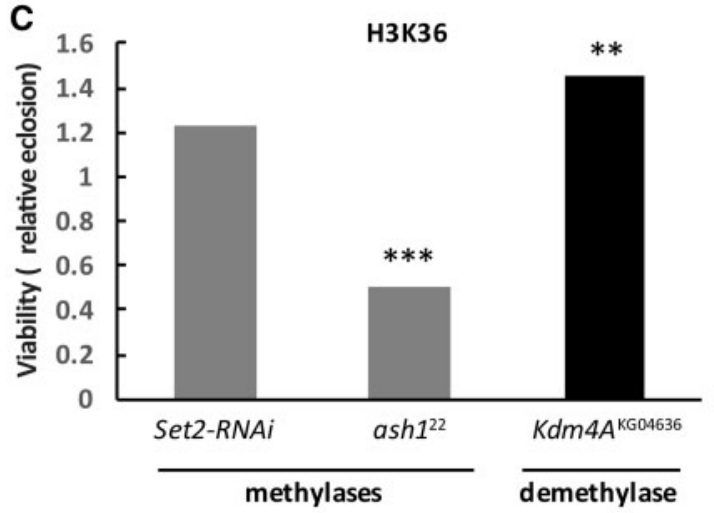

E

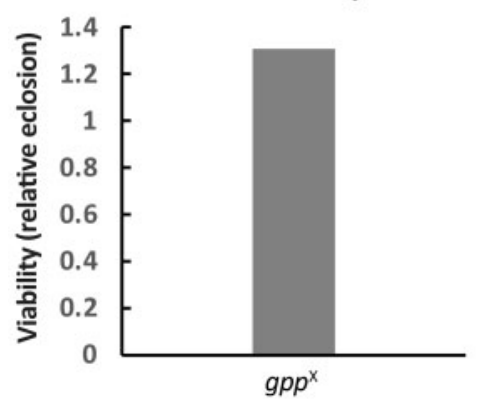

B
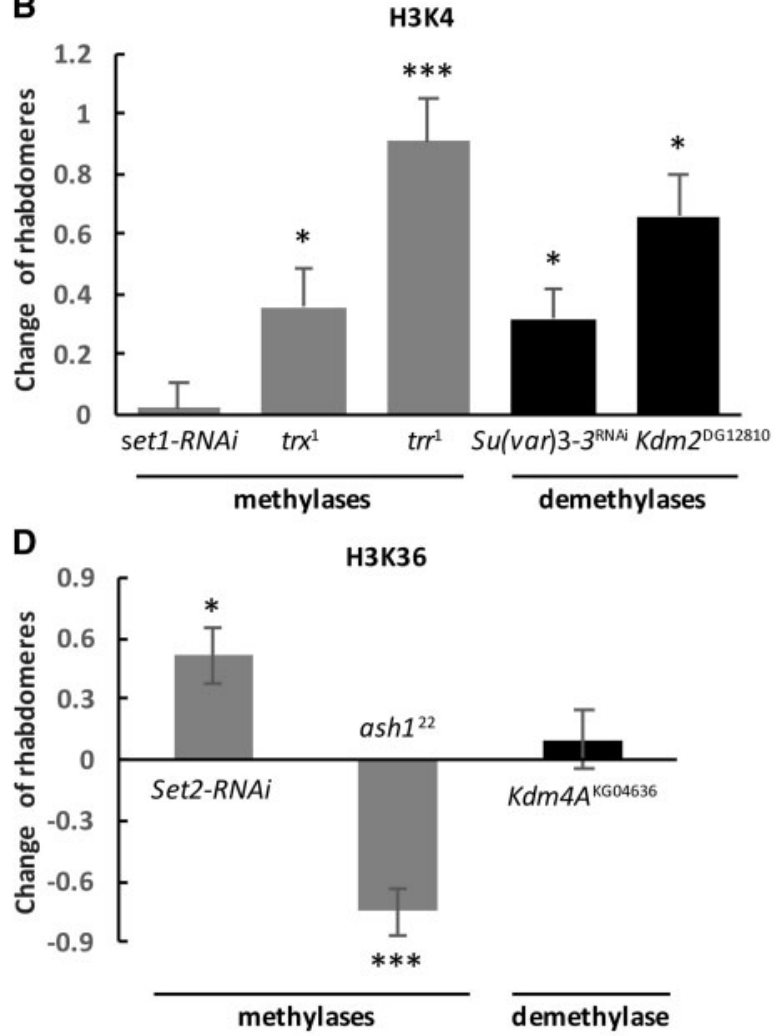

$\mathbf{F}$

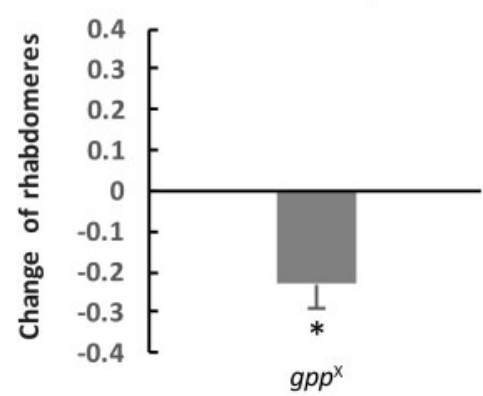

Figure 1. Methylases and demethylases acting on active marks H3K4 (A and B), H3K36 (C and D) and H3K79 (E and F) had varying effect on HD pathology. The graphs on the left show the effects of heterozygous loss of (A) H3K4, (C) H3K36, or (E) H3K79-specific methyltransferases and demethylases on Httex1p-Q93-induced reduced viability. Bars show relative eclosion calculated as the following ratio of eclosed progeny: ((Htt-expressing methylation mutants)/(Htt-expressing controls))/((Htt-non-expressing methylation mutants)/(Htt-non-expressing controls)). The graphs on the right show the effects of heterozygous loss of (B) H3K4, (D) H3K36 or (F) H3K79-specific methyltransferases and demethylases on Httex1p-Q93-induced neurodegeneration. Bars show the differences of average number of rhabdomeres per ommatidium in the eyes of methylation mutant Htt expressing flies and Htt expressing control siblings. Error bars represent standard error of mean. Significant differences are marked by ${ }^{*} \mathrm{P}<0.05$, ${ }^{* *} \mathrm{P}<0.01,{ }^{* * *} \mathrm{P}<0.001$.

even stronger neurodegeneration (Supplementary Material, Fig. S1A and B).

Modulating histone marks specific for constitutive heterochromatin has limited impact on Htt pathology

Next we investigated the effects of enzymes modulating epigenetic marks specific for constitutive heterochromatin, H3K9 and H4K20 methylation, on HD pathogenesis.

H3K9 trimethylation represents a specific mark for epigenetic repression that recruits the Su(var)205/HP1 protein to methylated histones, which then induces heterochromatin formation (58-60). Three SET domain containing lysine methyltransferases are responsible for methylating the H3K9 residue in fruit flies: Eggless (Egg), the Drosophila ortholog of human SETDB1 and mouse ESET (61-63); Su(var)3-9, the Drosophila ortholog of human Su(var)3-9 (64); and G9a, the Drosophila ortholog of human and mouse G9a $(65,66)$. These enzymes have different expression patterns, preferred methylation substrates and functions (67).

Mutants or transgenic insertion lines of each of the three genes were tested for effects on HTT-mediated degeneration. Heterozygous reduction using a loss of function allele of eggless, egg $^{1473}$ (68) did not have any significant effect on either viability (1.29 relative elosion, N.S. Fig. 2A) or neurodegeneration ( -0.1 change of rhabdomeres per ommatidium, N.S., Fig. 2B). Testing with an independent loss of function allele egg $^{235}$ (68) gave similar results (Supplementary Material, Fig. S2A and B). 
Heterozygous reduction of Su(var)3-9 with an amorphic allele Su(var)3-9 $9^{1}$ (69) resulted in no effect on neurodegeneration $(+0.21$ change of rhabdomeres per ommatidium, N.S., Fig. 2B) albeit reduced viability (relative eclosion of $0.69, P=0.02$, Fig. 2A) in Htt-challenged flies. Testing with an independent amorphic allele, Su(var)3-9 $9^{2}$ (70), gave similar result on neurodegeneration but ameliorated viability (Supplementary Material, Fig. S2A and B).

An RNAi line for G9a, GD9876, was confirmed by Q-RT-PCR to reduce G9a mRNA levels to $63 \%$ of control (Supplementary Material, Fig. S2C). Htt G9a-RNAi/+ flies showed similar viability relative to control $\mathrm{Htt}+/+(0.96$ relative eclosion, N.S., Fig. $2 \mathrm{~A})$ and a non-significant change of rhabdomeres per ommatidium $(+0.17$, N.S., Fig. 2B). Heterozygous reduction using allele $\mathrm{G}^{\mathrm{MB}} \mathrm{a}^{\mathrm{MB} 1975}$, in which a Gal4 enhancer trap element is inserted into the second exon of the gene, also did not significantly alter neurodegeneration but did reduce viability (Supplementary Material, Fig. S2A and B).

The effect on HD pathology of reducing the activity of the H3K9 demethylases that exert the opposing activity was examined. JmjC-domain containing histone demethylase 2 (JHDM2), was shown previously to specifically demethylate H3K9 (71). Heterozygous reduction of JHDM2 (JHDM2 $2^{\mathrm{KGO} 0644} /+$ ) did not affect neurodegeneration significantly $(-0.25$ change of rhabdomeres per ommatidium in Htt JHDM2/+ versus $\mathrm{Htt}+/+$, N.S., Fig. 2B) but improved viability (relative eclosion of $1.60, P=4 \times$ $10^{-5}$, Fig. $2 \mathrm{~A}$ ) compared with the controls.

The demethylase encoded by the Lysine (K)-specific demethylase $4 \mathrm{~B}(\mathrm{Kdm} 4 \mathrm{~B})$ gene was shown to act on both $\mathrm{H} 3 \mathrm{~K} 9$ and $\mathrm{H} 3 \mathrm{~K} 36$ residues (72). Using heterozygous $K d m 4 B^{03531}$, a P element insertion allele that results in substantial reduction in $\mathrm{Kdm} 4 \mathrm{~B}$ protein levels in heterozygotes (73), we did not observe a significant impact on either viability (relative eclosion rate of 1.10 , N.S., Fig. 2A) or neurodegeneration (+0.13 change of rhabdomeres per ommatidium, N.S., Fig. 2B).

Similar to H3K9 methylation, H4K20 mono- or tri-methylation represents a specific mark for epigenetic transcriptional repression. H4K2O trimethylation is mainly enriched in pericentric heterochromatin regions where it plays a central role in the establishment of constitutive heterochromatin (74). PR/SET domain containing protein 7 (PR-Set7) specifically acts to mono-methylate $(75,76)$ whereas histone methyltransferase 4-20 (Hmt4-20) is responsible for di- and tri-methylating H4K20 (77). We tested the effects of the hypomorphic PR-Set ${ }^{1}$ allele (78) on Htt-induced pathology and did not see any significant impact on either viability

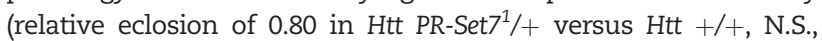
Fig. $2 \mathrm{C})$ or neurodegeneration $(+0.05$ change of rhabdomeres per ommatidium, N.S., Fig. 2D). Similarly, the Hmt4-20 ${ }^{K G 01771}$ allele, an allele with a P-element inserted in the 5' untranslated region (UTR) of the Hmt4-20-RA transcript, did not result in any significant difference in Htt Hmt4-20/+ flies compared to their control siblings $(\mathrm{Htt}+/+)$ in either viability (relative eclosion of 0.91, N.S., Fig. $2 \mathrm{C})$ or change of rhabdomeres per ommatidium (+0.23, N.S., Fig. 2D).

Based on the results described earlier involving mutant Huntingtin and H3K9 methyltransferases and demethylases and H4K20 methyltransferases, we conclude that modulating constitutive heterochromatin marks does not exert a significant impact on HTT-mediated HD pathology in Drosophila.

\section{Altered levels of enzymes modulating the facultative heterochromatin mark H3K27me3 impact HD pathology}

Tri-methylated lysine 27 on histone $\mathrm{H} 3$ (H3K27me3) is the most well-characterized mark for 'facultative heterochromatin' and is
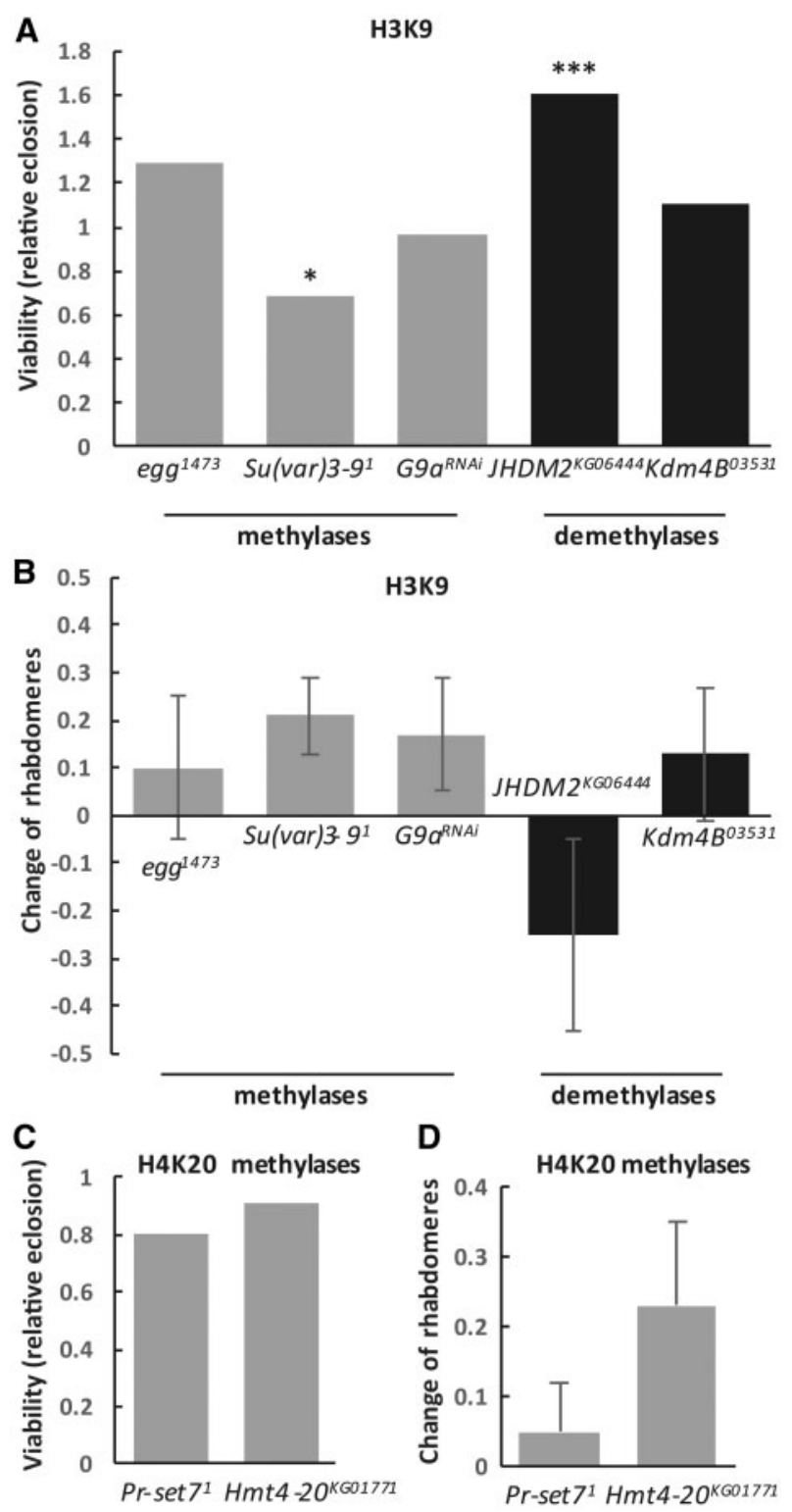

Figure 2. Modulating constitutive heterochromatin marks H3K9 and H4K2O methylation has no effect on HD pathology. (A) The effects of heterozygous loss of H3K9-specific methyltransferases and demethylases on Httex1p-Q93-induced reduced viability. Bars show relative eclosion calculated as the following ratio of eclosed progeny: ((Htt-expressing methylation mutants)/(Htt-expressing controls) $) /($ (Htt-non-expressing methylation mutants)/(Htt-non-expressing controls)). (B) The effects of heterozygous loss of H3K9-specific methyltransferases and demethylases on Httex1p-Q93-induced neurodegeneration. Bars show the differences of average number of rhabdomeres per ommatidium in the eyes of methylation mutant Htt expressing flies and Htt expressing control siblings, error bars represent standard error of mean. (C) The effects of heterozygous loss of H4K20-specific methyltransferases on Httex1p-Q93-induced reduced viability. Bars show relative eclosion. (D) The effects of heterozygous loss of H4K20-specific methyltransferases on Httex1p-Q93-induced neurodegeneration. Differences of average number of rhabdomeres per ommatidium in the eyes of methylation mutant Htt expressing flies and Htt expressing control siblings are shown. Error bars represent standard error of mean. Significant differences are marked by ${ }^{*} \mathrm{P}<0.05,{ }^{* *} \mathrm{P}<0.01,{ }^{* * *} \mathrm{P}<0.001$.

critical for the repression of key transcriptional regulators during development (79). It was previously reported that full length Huntingtin acts as a facilitator of the multi-subunit histone H3 lysine 27 (H3K27) methyltransferase complex Polycomb Repressive 
Complex 2 (PRC2) in mice, and mouse embryos lacking Huntingtin display a series of phenotypes similar to that of PRC2-deficient embryos (80). We asked if modulation of enzymes acting on the H3K27me3 repressive mark influences expanded polyQ Huntingtin-induced pathology. The PC-G protein E(z) is the only protein found so far to be responsible for methylating H3K27 in Drosophila (81-83). Also, while there are multiple H3K27me3specific demethylases, including UTX, UTY and JmjD3 in mammalian cells, Drosophila have a single histone demethylase, Utx, capable of specifically demethylating di- and tri-methylated H3K27 (84). The fact that there is only one enzyme catalyzing each direction of methylation/demethylation makes testing H3K27-specific enzymes straightforward in Drosophila.

The null allele $E(z)^{731}$ has a nonsense mutation within the SET domain, the catalytic part responsible for the methyltransferase activity, and produces no detectable protein (82). When compared with Htt expressing control flies, Htt-expressing flies heterozygous for $E(z)^{731} /+$ had significantly lower viability (relative eclosion of $0.54, P=3.0 \times 10^{-7}$, Fig. $3 \mathrm{~A}$ ) as well as significantly fewer rhabdomeres per ommatidium ( -0.34 less rhabdomeres per ommatidium compared to the control, $P=0.02$, Fig. 3B). Significant reduction in viability $(79 \%$ relative eclosion rate, $P=0.004)$ and neurodegeneration $(-0.48$ less rhabdomeres per ommatidium compared to control, $P=0.008$ ) was also observed with another null allele, $E(z)^{63}$ (Supplementary Material, Fig. S3A and B). These results indicate that reducing the $\mathrm{E}(\mathrm{z})$ methylase enhances $\mathrm{HD}$ pathology.

However, $\mathrm{E}(\mathrm{z})$ does not function as a single enzyme but as the catalytic subunit of the PRC2 protein complex (81), which besides $E(z)$, contains three core subunits: Extra sex combs (Esc, human EED ortholog in Drosophila), Suppressor of zeste-12 $(\mathrm{Su}(\mathrm{z}) 12)$, and nucleosome-remodeling factor 55 (NURF-55) $(81,82)$. Esc is a WD repeat containing protein which binds specifically to trimethylated $\mathrm{H} 3 \mathrm{~K} 27$ whereas $\mathrm{Su}(\mathrm{z}) 12$ is proposed to bind E(z) and promote PRC complex assembly (85). Both Esc and $\mathrm{Su}(\mathrm{z}) 12$ are required for the integrity of PRC2 and PRC-mediated H3K27 methylation $(86,87)$. To investigate possible interactions of Htt with these components of the PRC2 complex, we carried out genetic interaction tests with mutant alleles of Esc and $\mathrm{Su}(\mathrm{z}) 12$ as well as non-core components of PRC2. Similar to E(z), heterozygous reduction of Esc by the esc ${ }^{5}$ null allele enhanced pathology. We observed severely reduced viability (relative eclosion of $0.16, P=1.50 \times 10^{-12}$, Fig. $3 \mathrm{~A}$ ) and significantly enhanced neurodegeneration $(-0.52$ less rhabdomeres per ommatidium in $\mathrm{Htt} \mathrm{esc} /$ + versus $\mathrm{Htt}+/+$ flies, $\mathrm{P}=0.02$, Fig. 3B). Heterozygous reduction of $\mathrm{Su}(\mathrm{z}) 12$ by the loss of function allele $\mathrm{Su}(\mathrm{z}) 12^{3}$ also resulted in significantly enhanced neurodegeneration ( -0.69 less rhabdomeres in $\mathrm{Htt} \mathrm{Su}(\mathrm{z}) 12^{3} /+$ than in $\mathrm{Htt}+/+, \mathrm{P}=0.0007$, Fig. 3B) albeit positive impact on viability (1.30 relative eclosion, $P=0.03$, Fig. $3 \mathrm{~A})$. In contrast, when we tested two non-core components of PRC2, Pcl and Jing, we did not observe any significant impact on HD pathology (Supplementary Material, Fig. S3A and B). However, reduced levels of a third non-core PRC2 component, Jarid2, by heterozygous Jarid2 ${ }^{\mathrm{MBO} 0996}$ null allele suppressed HD pathology as evidenced by significantly higher average number of rhabdomeres per ommatidium $(+0.54$ more than in controls, $P=0.008$, Supplementary Material, Fig. S3B) and increased viability (3.18 relative eclosion rate, $P=2.8 \times 10^{-15}$, Supplementary Material, Fig. S3A). As a comparison, we also tested Pc, a core component of PRC1, which also compacts chromatin but catalyzes H2A monoubiquitylation independently of PRC2 and H3K27me3 (88), and saw no significant effect on the survival of photoreceptor neurons $(-0.23$ less rhabdomeres per ommatidium in $\mathrm{Htt} \mathrm{Pc}^{1} /+$ than $\mathrm{Htt}+/+$, N.S., Supplementary Material,
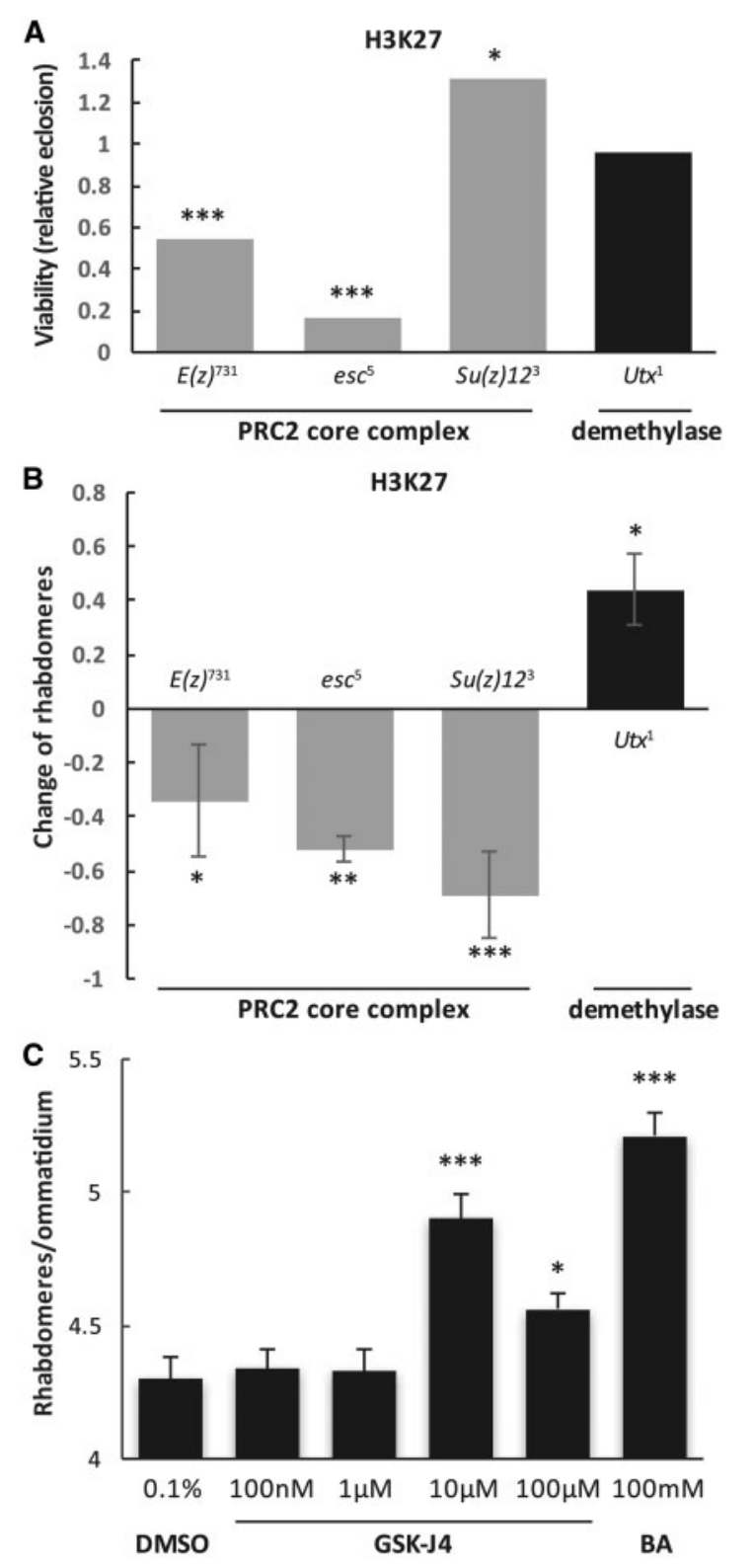

Figure 3. Modulating H3K27 methylation has specific effect on HD pathology. (A) The effects of heterozygous loss of subunits of the H3K27-specific PRC2 methyltransferase complex and Utx demethylase on Httex1p-Q93-induced reduced viability. Bars show relative eclosion calculated as the following ratio of eclosed progeny: ((Htt-expressing methylation mutants)/(Htt-expressing controls))/((Htt-non-expressing methylation mutants)/(Htt-non-expressing controls)). (B) The effects of heterozygous loss of PRC2 subunits and Utx on Httex1pQ93-induced neurodegeneration. Bars show the differences of average number of rhabdomeres per ommatidium in the eyes of methylation mutant Htt expressing flies and Htt expressing control siblings. Error bars represent standard error of mean. (C) Utx inhibitor GSK-J4 is neuroprotective as shown by the significantly improved photoreceptor neuron survival at concentrations of 10 and $100 \mu \mathrm{M}$ concentrations in flies challenged with Httex1p-Q93. No change in neurodegeneration was observed in the $0.1 \%$ DMSO vehicle control. $100 \mathrm{mM}$ butyric acid served as positive control. Significant differences are marked by ${ }^{*} \mathrm{P}<0.05,{ }^{* *} \mathrm{P}<0.01,{ }^{* * *} \mathrm{P}<0.001$.

Fig. S3 B) albeit $\mathrm{Htt}^{\mathrm{Pc}} 1 /+$ showed improved viability compared to $\mathrm{Htt}+/+$ control flies (relative eclosion of 1.99, $\mathrm{P}=0.003$, Supplementary Material, Fig. S3A).

Based on the above, we reasoned that reducing the activity of demethylase Utx that exerts an opposite enzymatic function 
on H3K27me3 might rescue HD pathology. First we tested the $U_{t x}{ }^{1}$ allele, which has a premature termination codon in the JmjC domain and is a strong hypomorph (89). Consistent with our predictions, heterozygous $U t x^{1}$ rescued the HD neurodegeneration phenotype, with the number of rhabdomeres per ommatidium significantly higher in $\mathrm{Htt} \mathrm{Utx}^{1} /+$ flies compared with Htt-expressing control flies $(+0.44$ more rhabdomeres per ommatidium, $P=0.02$, Fig. $3 \mathrm{~B}$ ) while it had no significant impact on viability (relative eclosion of 0.96 , N.S., Fig. 3 A). Testing a second allele, $U t^{2}{ }^{2}$, which contains a missense mutation in the $C$ terminus resulting in a reduced amount of Utx protein (89), also gave similar results (Supplementary Material, Fig. S3A and B). Therefore, contrary to the effect of reducing $\mathrm{E}(\mathrm{z})$, heterozygous reduction of Utx ameliorates mutant Huntingtin-induced neurodegeneration. Thus, manipulations that tend to increase H3K27 methylation (e.g. lower Utx) tend to rescue HTT-induced pathology while those that tend to decrease H3K27 methylation (e.g. reducing PRC2 core complex components) lead to more aggressive pathology.

Recently, a small molecule, GSK-J1, was developed to be a selective catalytic site inhibitor of H3K27me3-specific jumonji JMJ subfamily of proteins (90). Drosophila H3K27me3-specific demethylase Utx contains all the critical amino acids involved in GSK-J1 binding (data not shown). Since reducing Utx activity genetically rescued HD pathology, we explored the possibility of rescuing the HD pathology pharmacologically with this Utx inhibitor. We compared the effect of increasing concentrations of the H3K27me3-specific inhibitor, the cell-penetrating ester prodrug GSK-J4, butyrate (BA, positive control) and dimethyl sulfoxide (DMSO) (negative control). As a histone deacetylase inhibitor shown in previous studies (35), BA is neuroprotective as Htt-expressing flies raised on $100 \mathrm{mM}$ BA had significantly higher average number of rhabdomeres per ommatidium than DMSO treated ones (5.21 versus $4.3, P=4.05 \times 10^{-9}$, Fig. $3 C$ ). Interestingly, flies on the higher concentrations (10 and $100 \mu \mathrm{M}$ ) of GSK-J4 showed higher number of rhabdomeres per ommatidium, with the average of 4.9 for $10 \mu \mathrm{M}$ and 4.65 for $100 \mu \mathrm{M}$, which are both significant higher compared with the $0.1 \%$ DMSO control $\left(P=2.00 \times 10^{-5}\right.$ and $P=0.05$, respectively. Fig. $\left.3 C\right)$. The improvement by $10 \mu \mathrm{M}$ GSK-J4 was not due to the reduction of the level of soluble Huntingtin (Supplementary Material, Fig. S4). In contrast, flies on the lower concentrations (100 nM and $1 \mu \mathrm{M}$ ) of GSK-J4 showed no difference relative to the DMSO control (Fig. 3C). We also tested transferring the Htt-expressing flies to the drug-containing food after their eclosion but saw no difference between GSK-J4 and DMSO treatment (data not shown). Thus both genetically and pharmacologically, manipulation of the methylation activity of Utx holds promise as a novel therapeutic drug target for ameliorating HD symptoms.

\section{Partial loss of Utx reduces Htt protein aggregation}

As genetic factors mediating H3K27 methylation or demethylation showed opposite effects on mutant HTT-induced phenotypes suggesting a potentially attractive therapeutic target, we decided to further investigate the potential involvement of Utx in HD pathology. First, we needed to exclude the possibility that reduced Utx ameliorates HD phenotypes in the model because Htt transgene expression per se is affected by Utx mutations. We performed q-RT-PCR analysis on Htt-challenged Utx mutant (elav-GAL4/w; Utx ${ }^{1 /+}$; UAS-Httex1p-Q93/+) or Htt-challenged control siblings (elav-GAL4/w; +/+; UAS-Httex1p-Q93/+) and found no significant difference in the level of Htt expression in
$U^{1} x^{1}$ heterozygotes (Fig. 4A). Similar results were also obtained with Utx ${ }^{2}$ heterozygotes (Supplementary Material, Fig. S3C). This indicates that the rescuing effect of Utx reduction on HD pathology is not due to a reduced level of Htt transgene expression.

As aggregation of mutant Htt is a hallmark feature of HD, we investigated whether reducing Utx affects HTT protein accumulation and aggregation. To test this, we drove the expression of mutant Huntingtin exon1 in neurons with elav-GAL4 in the presence or absence of Utx mutations and examined Htt protein accumulation and aggregation in larval eye discs. When the tissues were immuno-stained with $\mathrm{Htt}$ exon1-specific antibody (VB3130), we observed stronger Htt protein aggregation with the expression of Httex1p-Q120 compared with Httex1p-Q93, therefore we used Httex1p-Q120 for further immunofluorescence image analysis (Fig. 4B). By counting Htt aggregate-positive puncta on compiled 3D images, we found that eye discs of Htt expressing flies heterozygous for Utx (elav-GAL4/+; Utx ${ }^{1 /+}$; UASHttex1p-Q120/+) had significantly less HTT puncta than eye discs of control siblings (elav-GAL4/+; +/+; Httex1p-120Q/+) (Fig. 4C). This result indicates that heterozygous reduction of Utx decreased the level of HTT protein aggregation.

\section{Interrogation of H3K27 methylation levels detects no change in HD flies}

Our genetic interaction tests suggested that expression of mutant Htt might lead to decreased H3K27 methylation and reduction of Utx activity might have rescued neurodegeneration by correcting the histone methylation imbalance. To test this possibility, we first investigated whether global H3K27 trimethylation was affected by Htt expression. We quantified the level of H3K27me3 in the heads of flies expressing Httex1p-Q93 versus Httex1p-Q20 controls by the elav-GAL4 driver using quantitative western blot analysis (Fig. 4D and E). In contrast of the significantly diminished H3K27me3 levels in larval samples of $E(z)$ null trans-heterozygotes $E(z)^{731} / E(z)^{63}$ (Lane 15 in Fig. 4D) relative to $E(z)^{731} /+$ heterozygotes (Lane 14 in Fig. 4D), we did not observe any significant decrease in H3K27 trimethylation level in fly head samples from either sex expressing Httex1p-Q93 (Lane 2-7) compared to Httex1p-Q20 controls (Lane 8-13 in Fig. 4D, quantification in Fig. 4E), suggesting a lack of effect from HTT challenge on global level of H3K27me3 in HD flies.

Although we did not detect a global change in H3K27me3 levels in HTT expressing flies it is possible that HD challenge modifies the H3K27me 3 marks on specific genes. We tested this by chromatin immunoprecipitation (ChIP). From the publically available modENCODE Drosophila adult head H3K27me3 ChIP-Chip or ChIP-seq datasets (91) (no. 372-male, ChIP-Chip; no. 346-female, ChIP-Chip; no. 820-male, ChIP-seq), we identified a common set of 708 genes which, with $1 \mathrm{~kb}$ flanking sequences, overlap H3K27me3 enriched chromatin regions. We queried these 708 putatively H3K27me3 regulated genes for expression in adult heads using the modENCODE high-throughput RNA-seq data (92) and selected a set of 16 genes for ChIP-qPCR analysis, including genes that are not expressed (ato, eve, gsb-n, Ubx; Reads Per Kilobase of transcript per Million mapped reads $(\mathrm{RPKM})=0$ ), or expressed in low (eyg, caup, E5, due, mirr; RPKM < 10), moderate (Idgf3, hth, mAcR, srp, nAcR-beta21C; $20<\mathrm{RPKM}<50$ ) or high levels (ninaC, Obp99c; RPKM > 200) in heads of 4 day old females. We prepared chromatin from heads of 3 day old Httex1p-Q93 (mutant) or Httex1p-Q20 (control) expressing flies and performed ChIP-qPCR analysis with $\mathrm{H} 3$ and 

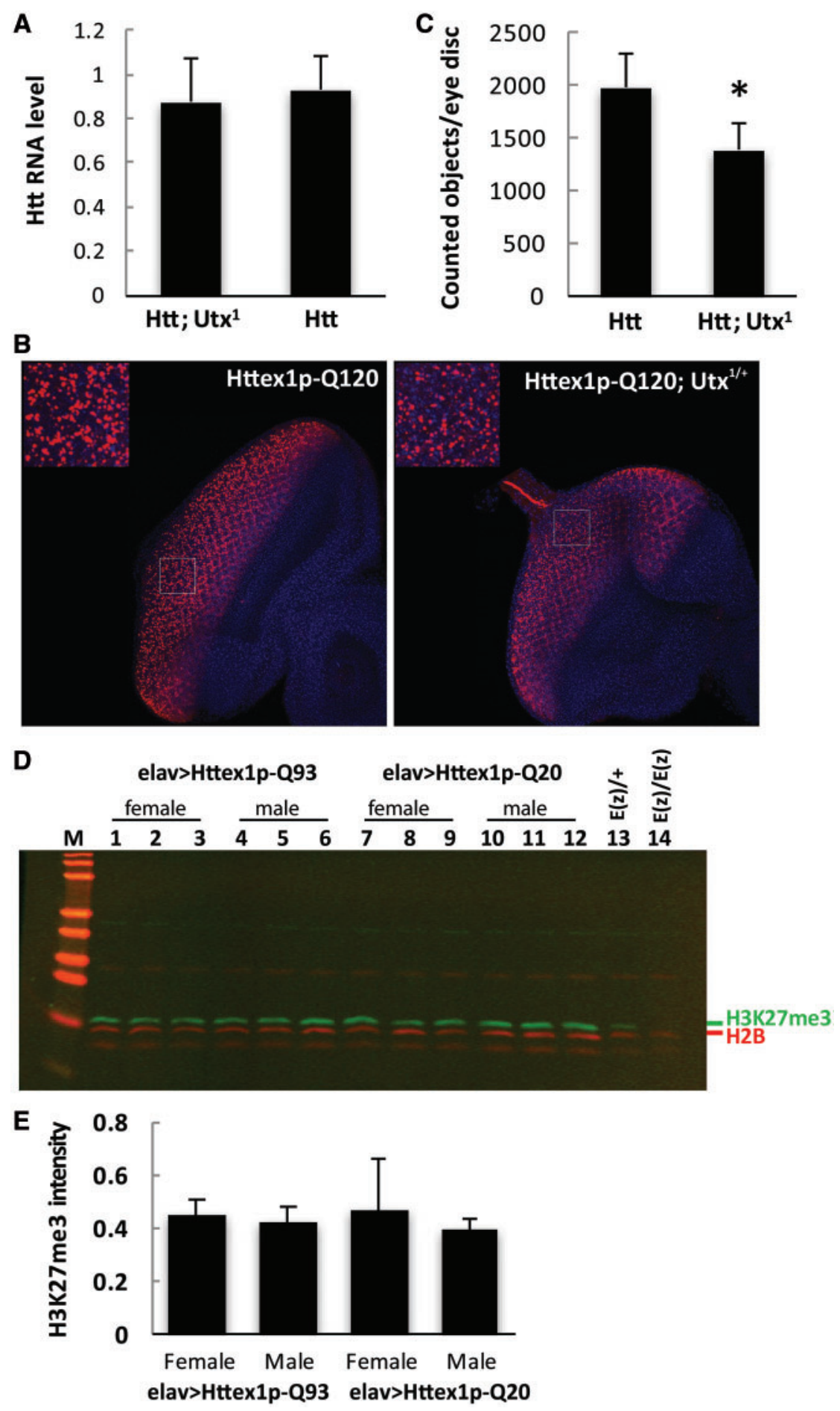

Figure 4. Reduction of Utx reduces Htt protein accumulation and aggregation but mutant Htt does not affect the methylation state of Utx targeted H3K27. (A) Heterozygous reduction of Utx ${ }^{1}$ does not have a significant effect on Htt transgene expression as measured by Q-RT-PCR. (B) Htt protein accumulation and aggregation in eye discs of elav-GAL4/+; Utx ${ }^{1} /+$; Httex1p-Q120/+ larvae (right) is reduced compared with control elav-GAL4/+; Httex1p-Q120/+ larvae (left). Representative compiled 3D confocal Z-stack images of fluorescent eye discs dissected from third instar larvae from indicated genotypes are shown. Insets show magnified views of areas outlined with white rectangles. Tissues were stained with $\alpha$-Htt antibody (1:2K VB3130, red) and Hoechst (blue). Images were taken at the same settings. (C) Quantification of $\alpha$-Htt positive puncta in eye discs by 3D Object counting function of ImageJ ( $n \geq 4)$ shows that heterozygous reduction of Utx results in reduced Htt aggregation. (D) Representative quantitative western blot showing similar signals from Htt challenged (elav-GAL4 > Httex1p-Q93) or non-challenged (elav-GAL4 > Httex1p-Q20) heads. Histones prepared from heads of females or males were probed on western blots with anti-body specific for trimethylated histone H3K27 (Millipore 07-449). Lanes 13 and 14 show diminished H3K27me3 signal from histones prepared from transheterozygotes (Lane $\left.14, E(z)^{731} / E(z)^{63}\right)$ compared to heterozygotes (lane 13, E(z)/+). Three biological replicates were analyzed for females and males of each genotype. (E) Quantification of H3K27me3 signal intensities normalized to H2B signal from western blots show similar levels in elav-GAL4 > Httex1p-Q93 and elav-GAL4 > Httex1p-Q20 male and female head samples. 
H3K27me3-specific antibodies (Fig. 5). The H3K27me3 signal was at least an order of magnitude higher at all of the selected loci than in a control genomic region, F22. Furthermore, we found a moderately negative correlation between gene expression (modENCODE RNA-seq) and H3K27me3 enrichment data in both flies expressing mutant $(R=-0.58, P=0.019)$ or control $(R=$ $-0.47, P=0.067)$ HTT. Surprisingly, however, a statistically significant change in H3K27me3 levels between the mutant and control could not be detected (two-way analysis of variance (ANOVA)). This, together with the immunoblot data suggests that H3K27me3 methylation balance is not disturbed in mutant HTT challenged flies, therefore the rescuing effect of Utx is likely not acting by restoration of wild-type H3K27 methylation patterns.

\section{Direct manipulation of H3K27 residue by PTM mimetics}

As the primary function of Utx is thought to be the demethylation of the H3K27 lysine residue, it was surprising that we could not detect alteration in trimethylated-H3K27 levels in HD flies. To further investigate whether the methylation state of the H3K27 influences HD pathology, we decided to manipulate this residue directly using PTM mimicking transgenes. The nonessential endogenous His3.3A gene is located outside of the histone gene cluster, transcribed in a replication independent manner and was shown to replace canonical H3 in active genes $(93,94)$. We generated flies carrying transgenes of histone variant His3.3A (UAS-His3.3A) or its point mutant forms mimicking His3.3A being methylated (UAS-His3.3A-K27M, lysine mutated to methionine) or unmodified (UAS-His3.3-K27R, lysine mutated to arginine) at the K27 position. To test the effects of His3.3AK27 PTM mimetics on HTT-induced phenotypes while minimizing developmental defects induced by histone mimetics, we limited transgene expression to the adult nervous system using a heat sensitive allele of the GAL80 transcriptional regulator $\left(\mathrm{GAL} 80^{\text {ts }}\right.$ ) that inhibits GAL4 driven transcription at $18^{\circ} \mathrm{C}$ but relieves it from repression at $30^{\circ} \mathrm{C}$. To reduce His $3.3 \mathrm{~A}$ gene load, we performed these experiments on flies heterozygous or homozygous for the His $3.3 \mathrm{~A}^{\mathrm{KO}}$ null mutation. For the tests, we raised flies expressing UAS-Httex1p-Q120 and one of the UAS-His3.3A transgenes simultaneously under the combined influence of the elav-GAL4 driver and tub-GAL80 $0^{\text {ts }}$ at $18^{\circ} \mathrm{C}$, and transferred them to $30^{\circ} \mathrm{C}$ after they eclosed.

Since it is not practical to score for eclosion rate and rhabdomere changes in ommatidia in those flies, we tested other aspects of HD pathology induced by HTT expression, e.g. reduced longevity and impaired motor function (95). First, we determined the longevity of male HD flies expressing His3.3A PTM mimic mutations. In general, we found the shape of the survival curves of different experimental categories similar with 9-11 days median and 13-15 days maximum lifespans (Fig. 6A and C). The restricted mean lifespan of males heterozygous for His3.3A $\mathrm{A}^{\mathrm{KO}}$ and overexpressing Httex1p-Q120 along with either His3.3, His3.3A-K27R or His3.3A-K27M was 9.85, 10.09 and 9.75, respectively (Fig. 6B). Based on statistical analysis of the data, the lifespan difference of HD flies overexpressing His3.3A-K27R and controls overexpressing His3.3A is statistically significant $(P=0.04$, log-rank test with Bonferroni correction), although the effect size is minute. The restricted mean lifespan of males homozygous for His $3.3 \mathrm{~A}^{\mathrm{KO}}$ and overexpressing Httex1p-Q120 along with either His3.3, His3.3A-K27R or His3.3A-K27M was 10.62, 10.74 and 9.97 respectively (Fig. 6D). In this case the lifespan difference between HD flies overexpressing His3.3A-K27M, and His3.3A or His3.3A-K27R are both

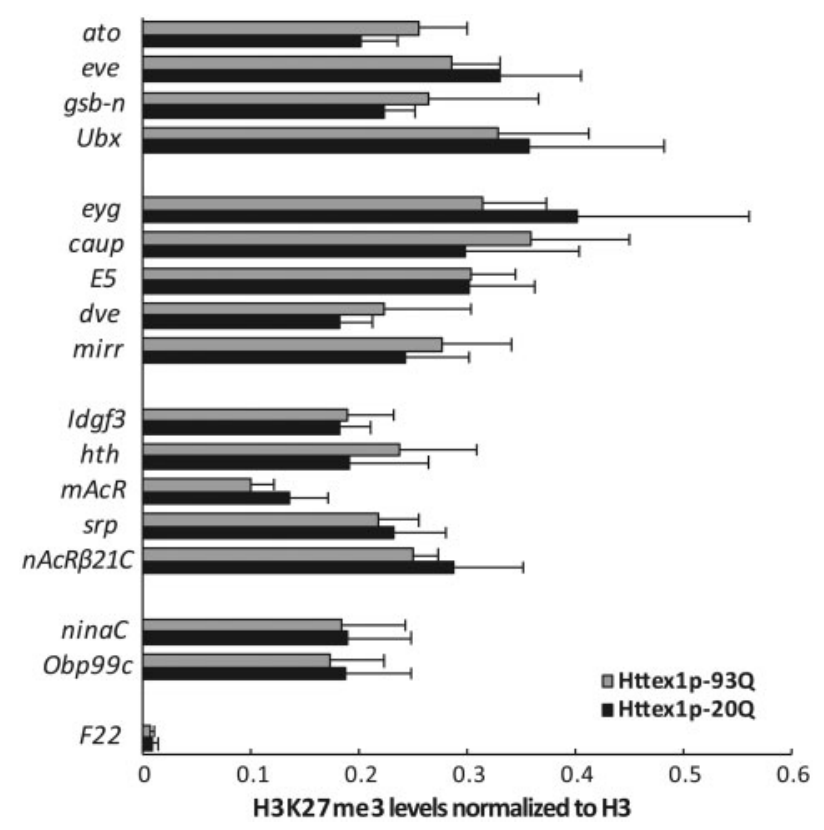

Figure 5. H3K27me3 occupancy is not altered on candidate genes in mutant Htt expressing flies. The level of H3K27me3 modification on genes with H3K27me3 enriched regions was determined by ChIP-qPCR in head samples of Httex1p-Q93 or Httex1p-Q20 (control) expressing flies. The tested gene set included genes not expressed in neurons (ato, eve, gsb- $n, U b x$ ), and ones with low (eyg, caup, E5, dve, mirr), moderate (Idgf3, hth, mAcR, srp, nAcR-beta21C) or high (ninaC, Obp99c) expression levels, and a negative control region (F22) was also included. Significant differences were observed in ChIP signal intensity between the tested loci $\left(P=1.04 \times 10^{-5}\right.$, two-way ANOVA) but not in H3K27me3 levels between Httex1p-Q93 and Httex1p-Q20 expressing flies $(P=0.961$, two-way ANOVA). Bars show the ratio of average ChIP-qPCR signals for H3K27me3 normalized to total input control and that for histone H3. Error bars represent standard error of mean $(n=3)$.

statistically significant $(P=0.0009$ and 0.0001 , respectively, log-rank test with Bonferroni correction). Thus, survival data suggest that introduction of His3.3A-K27 methylation mimetics slightly decrease survival while hindering modification of the K27 residue slightly increases it.

Next, we used a climbing assay to determine the motor abilities of HD flies expressing histone PTM mimetics. To characterize climbing ability, we determined the percentage of 10 day old HD flies overexpressing His3.3A, His3.3A-K27R or His3.3A-K27M on a homozygous His $3.3 \mathrm{~A}^{\mathrm{KO}}$ background that climbed at least $2.5,5$ or $7.5 \mathrm{~cm}$ vertically in $10 \mathrm{~s}$ (Fig. 6E). We found no significant differences in the climbing abilities of flies of different genotypes in these tests. Both His3.3A-K27R and His3.3A-K27M overexpressing flies performed slightly better than His3.3A control, but these differences were not significant statistically $(P=0.29$, ANOVA).

\section{Arginine methyltransferases}

Beside lysine methyltransferases, we also tested two protein arginine methyltransferases (PRMTs) that fall into the Types I and II PRMTs protein groups. Members of both groups are capable of both monomethylating and dimethylating arginine. However, while Type I enzymes dimethylate the same terminal $\mathrm{N}$ atom of the guanidinium group of the Arg side chain generating asymmetric dimethylarginine; Type II enzymes catalyze the addition of a methyl group to each of the terminal $\mathrm{N}$ atoms, generating symmetric dimethylarginine (96). 

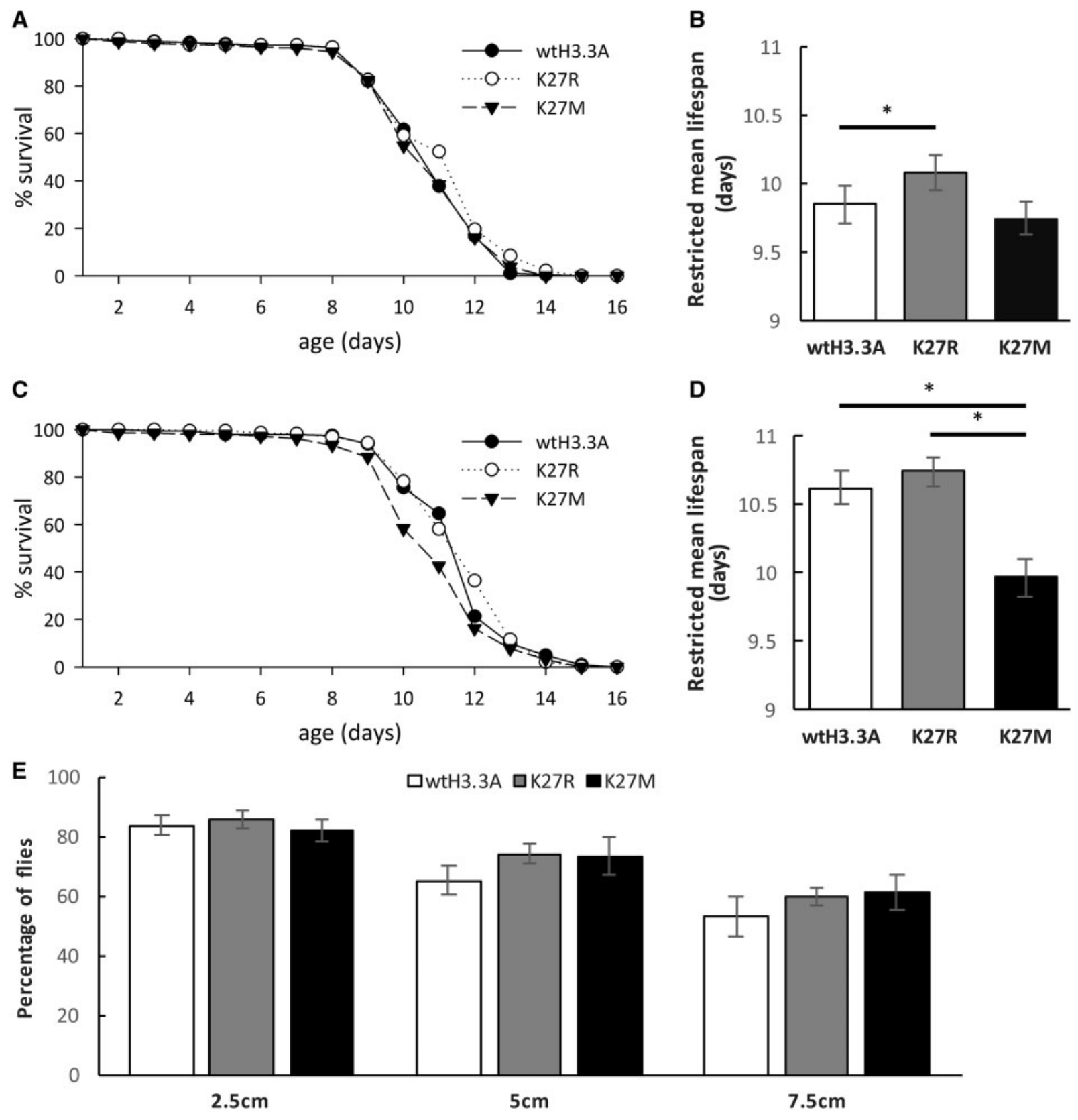

Figure 6. Direct manipulation of the H3K27 residue by PTM mimetic exert minor influence on HD pathology. The effects of H3K27 modifications on mutant Htt-induced reduced longevity and impaired motor activity were investigated in flies co-expressing UAS-Httex1p-Q93 and wild-type or point mutant UAS-His3.3A (wtHis3.3A, His3.3A-K27R or His3.3A-K27M) in the nervous system in a hetero- or homozygous His3.3 $\mathrm{A}^{\mathrm{KO}}$ background. (A) Survival plot shows percent survival of Httex1p-Q93 expressing males heterozygous for His3.3A ${ }^{K O}$ and co-expressing wtH3.3A $(n=185)$, H3.3A-K27R ( $\left.\mathrm{n}=225\right)$ or H3.3A-K27M ( $\left.n=255\right)$ as a function of time. (B) In heterozygous His3.3 $\mathrm{A}^{\mathrm{KO}}$ background expression of His3.3A-K27R slightly but significantly increases longevity $(P=0.0426$, log-rank test) of HD flies. Bars show restricted mean lifespan. Error bars represent SEM. (C) Percent survival of Httex1p-Q93 expressing males homozygous for His3.3A ${ }^{\mathrm{KO}}$ and co-expressing wtH3.3A ( $n=201$ ), H3.3A-K27R $(n=234)$ or H3.3A-K27M $(n=216)$ as a function of time. (D) In homozygous His $3.3 A^{\text {KO }}$ background expression of His3.3A-K27M significantly decreases longevity $(P=0.0009$, log-rank test) of HD flies. Restricted mean lifespan is shown. Error bars represent standard error of mean. (E) Motor activity of flies co-expressing UAS-Httex1p and wild-type or point mutant UAS-His3.3A were analyzed by the climbing assay. No significant difference between HD flies expressing wtH3.3A, H3.3A-K27R or H3.3A-K27M was found for the capability to climb at least 2.5, 5 or $7.5 \mathrm{~cm}$ vertically in $10 \mathrm{~s}$.

Art3 is the ortholog of human PRMT3 whose targets are unknown. We tested two mutant alleles: Art $3^{\mathrm{MIO} 3542}$, in which the second exon is disrupted by a Minos element, and Art3 $3^{\mathrm{c04615}}$, a PiggyBac transposon insertion in the first intron resulting in the reduction of the mRNA level of the gene below $1 \%$ of control (q-RTPCR data, not shown). Heterozygosity of Art3 ${ }^{\mathrm{MIO} 3542}$ significantly increased the viability of HD flies (1.47 eclosion rate, $\mathrm{P}=0.0005$,
Fig. 7A) but did not have a significant effect on neurodegeneration (+0.34 rhabdomeres per ommatidium in $\mathrm{Htt}$ Art3 $3^{\mathrm{MIO}} \mathrm{s} 42 /+$ versus $\mathrm{Htt}+/+$ control, N.S., Fig. 7B). The Art3 ${ }^{\mathrm{C} 04615}$ allele did not have a significant effect on either neurodegeneration $(+0.35$, N.S., Fig. 7B) or viability (0.77 eclosion rate, N.S., Fig. 7A).

FBX011 (CG9461), the ortholog of human FBXO11/PRMT9, is a Type II methyltransferase that is also a component of an SCF 
ubiquitin ligase (E3) complex. FBX011 participates in the regulation of apoptosis (97) and miRNA and siRNA silencing (98). Heterozygosity of $\mathrm{FBX011^{ \textrm {MBO } 0 7 4 9 }}$ allele, in which a Minos element disrupts the first exon of the gene, caused increased viability of HD flies (1.72 eclosion rate, $P=4.5 \times 10^{-6}$ ) while that of FBX011 ${ }^{\Delta 37}$ deletion allele did not have significant effect on the viability (relative eclosion rate of 1.19, N.S., Fig. 7A). Neither of the FBX011 alleles have influenced neurodegeneration (change of rhabdomeres per ommatidia is -0.10 in $\mathrm{Htt} F B X 011^{\Delta 37} /+$ versus control and +0.19 for $\mathrm{Htt} F B X 011^{\mathrm{MBO} 4449}$ versus control, N.S., Fig. 7B).

\section{Discussion}

Besides HD, pathology in a host of other CNS disorders has been correlated with transcriptional dysregulation including other polyQ diseases $(99,100)$, Alzheimer's (101), Parkinson's (102), amyotrophic lateral sclerosis (101) and Rubinstein-Taybi syndrome (103). In this study, we address the question whether enzymes affecting the status of protein lysine methylation, a PTM that has a profound effect on chromatin structure and gene expression, influence the pathology of HD. By altering the level of enzymes responsible for the correct formation of lysine methylation patterns, we found that methyltransferases and demethylases affect HD pathology in an intricate manner that suggests target locus-specific effects and raises the issue of methylation of non-histone proteins.

Our data reveal that manipulation of enzymes that regulate histone marks characteristic of constitutive heterochromatin has little or no effect on HD pathology. We found that methyltransferases modifying the $\mathrm{H} 4 \mathrm{~K} 20$ residue, PR-Set7 and Hmt4-20, did not exert a significant effect on HD pathology. Among the five H3K9-specific factors tested, only two influenced Htt-induced phenotypes: reducing Su(var)3-9 enhanced while reducing JHDM2 suppressed the negative effect of mutant huntingtin on viability. However, neither of these factors had an impact on degeneration of photoreceptor neurons. These results show that manipulation of several categories of methyl modifying loci associated with heterochromatin formation does not affect HD pathology and suggest that transcriptional dysregulation in HD is not due to major reconfiguration of constitutive heterochromatin. Thus, the enzymes acting on constitutive heterochromatic marks can be eliminated as attractive therapeutic candidates.

Analysis of functionally related genes encoding enzymes modifying activating epigenetic methyl marks-including methyltransferases and demethylases acting on the H3K4 residue, which is trimethylated on promoters of active genes, or on the $\mathrm{H} 3 \mathrm{~K} 36$ or $\mathrm{H} 3 \mathrm{~K} 79$ residues that are methylated on the body of transcribed genes-provided ambiguous results. We have previously reported reduced H3K4 trimethylation on promoters of down-regulated genes in R6/2 mice and human HD samples and showed that partial loss of the H3K4 trimethyl-specific demethylase Lid ameliorated HD pathology in Drosophila (7). The altered state of H3K4 methylation in post-mortem brain samples of HD patients was also observed in a study conducted by Dong and coworkers (104). However that analysis found no correlation between H3K4me3 levels at promoters and transcription levels, thus raising the possible involvement of nonhistone targets of these enzymes or more distal sites of action at distant enhancers of prefrontal cortex genes.

In this study, we found that reducing other H3K4-specific demethylases beside Lid, i.e. Su(var)3-3 and Kdm2, also rescued mutant Htt-induced toxicity and neurodegeneration. Unexpectedly, we
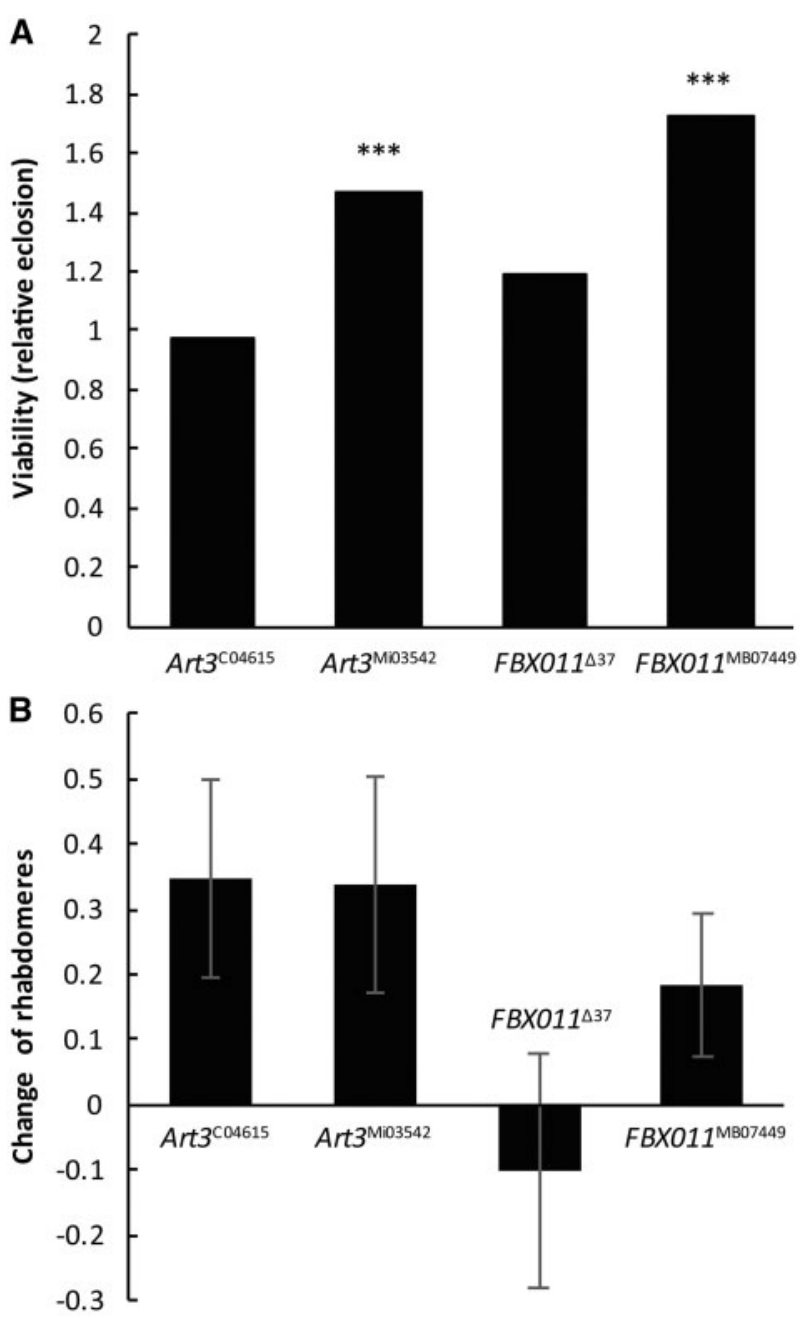

Figure 7. The effects of heterozygous reduction of PRMTs, Art3 or FBXO11 on mutant Htt-induced neurodegeneration and reduced viability. (A) Heterozygosity

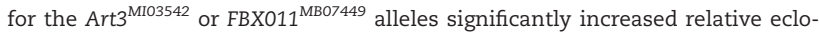
sion rate of Httex1p-Q93 expressing flies $\left(P=0.0005\right.$ and $P=4.5 \times 10^{-6}$, respectively), while other alleles, Art3 ${ }^{\mathrm{C} 0461}$ and $\mathrm{FBX} 011^{\triangle 37}$, did not have a significant effect. (B) None of the inspected alleles for Art3 or FBXO11 influenced the degeneration of photoreceptor neurons significantly. Bars show the difference of averages of number of rhabdomeres per ommatidium in the eyes of heterozygous PRMT mutant Htt expressing flies and Htt expressing control flies. Error bars represent SEM.

found that reduction of two out of the three tested H3K4-specific methyltransferases, Trx and Trr also suppressed neurodegeneration, although their effect on viability was opposite. Experiments aimed at testing enzymes modifying the H3K36 or H3K79 residues gave similarly gene-specific results: while partial loss of the H3K36specific methyltransferase Set2 ameliorated neurodegeneration, reduction of H3K36-specific Ash1 and the H3K79-specific methyltransferase Gpp enhanced it. Furthermore, heterozygous loss of the H3K36-specific demethylase Kdm4A had no effect on degeneration of photoreceptor neurons but increased viability.

The fact that modulating both the methylating and demethylating activities can have the same effect on HD pathology (e.g. H3K4 methylases and demethylases) points to the possibility of a complex set of epigenetically regulated disease modifying target loci and/or non-histone protein targets for those methylation modifying enzymes, which makes them a challenging therapeutic target. 
One of the most important findings of this study is that manipulation of enzymes that affect facultative heterochromatin (which is typically dynamically regulated chromatin) impact HD pathology. Specifically, we found that loss of function mutations of the catalytic subunit of the PRC2 complex, E(z), that is responsible for H3K27 trimethylation, enhances neurodegeneration, and similar effects were observed with other components of the PRC2 complex, Esc and Su(z)12. In contrast, reducing the amount or activity of the H3K27-specific demethylase, Utx, by genetic or pharmacological means ameliorated neurodegeneration and reduced HTT aggregation. These findings that identify Utx as an appealing target for potential HD therapeutic intervention are consistent with previous studies demonstrating the involvement of misregulated H3K27 methylation in several neurodegenerative disorders. For example, the murine PRC2 complex was shown to have a critical role in the maintenance of proper gene expression in medium spiny neurons (MSNs) that are most affected in HD, by repressing non-neuronal, non-MSN specific and cell death promoting genes (105). PRC2 deficiency of Ezh1 and Ezh2 in MSN neurons resulted in progressive fatal neurodegeneration, reduction of the number of striatal neurons and impaired motor performance with concurrent upregulation of non-MSN-expressed genes and downregulation of MSNspecific genes (105). In contrast, in the neurodegenerative disease ataxia-telangiectasia (A-T), reduced activity of PRC2 suppresses pathology. In a murine $\mathrm{Atm}^{-1-}$ knock-out model of A-T, increased stability and protein level of EZH2 led to a substantial increase in the number of H3K27me3 binding sites on chromatin and concurrent reduction of gene expression. This transcriptional change had a significant impact on A-T pathology as knock-down of Ezh2 in $\mathrm{Atm}^{-/-}$mice was protective, resulting in reduced caspase- 3 activation and Purkinje cell degeneration, and increased motor performance (106). PRC2 also modulates the severity of spinal muscular atrophy (SMA) by regulating the activity of the Survival Motor Neuron 2 (SMN2) gene, which is a duplicated gene highly similar to SMN1 that is mutated in SMA (107). In the case of Huntington's disease, beside the potential effects of PRC2 activity on neurodegeneration, the role of normal huntingtin in the regulation of protein methylation by PRC2 might influence pathology. It was previously reported that full-length murine huntingtin physically interacts with Ezh2 and Suz12 and increases the methyltransferase activity of PRC2 in vitro (80). Accordingly, mouse embryos lacking wild-type huntingtin exhibited decreased trimethylation of histone $\mathrm{H} 3$ at lysine 27 and failed to repress PRC2-regulated Hox gene expression (80).

Despite the phenotypic effects of the opposing H3K27-specific methyltransferase and demethlyase in our model, we did not find direct physical evidence that would suggest direct mHtt-induced changes in histone H3K27 modification: altered H3K27me3 levels could not be detected by either immunoblot or ChIP assays, and direct genetic manipulation of the H3K27 residue did not replicate the phenotypic changes observed in $E(z)$ or Utx mutants. This raises the possibility that improved pathology in response to manipulation of methyl modifying enzymes may be due either to non-histone targets of these proteins or to putative demethylase independent activities.

The activities of several methyltransferases and demethylases are not restricted to histones but they can also modify other proteins. For example, EZH2 methylates the transcriptional factors STAT3 and PLZF, which in the case of STAT3 leads to increased phosphorylation and enhanced activity (108) while in the case of PLZF; it leads to ubiquitylation and degradation of PLZF (109).
Another possibility besides the potential targeting of nonhistone proteins is that the effects that Utx mutants exert on HTT toxicity may be independent of the demethylase activity of the enzyme. It was demonstrated previously that mouse UTY, a Y chromosomal catalytically inactive paralog of UTX, partially complements the effects of loss of UTX activity (110). While Utx females and Utx $/$ Uty $^{-}$males never pass embryonic stage E18.5 of development, a significant portion of hemizygous Utx null males with a wild-type copy of Uty reach adulthood, suggesting that demethylase independent activities of UTX/UTY might be crucial during development. These activities might still involve transcriptional regulation, as both UTX and UTY were shown to directly bind to and potentiate the activity of heart-specific transcriptional factors $(110,111)$. Furthermore, UTX and UTY both physically interact with RBBP5, an H3K4 methyltransferase complex subunit, and the SWI/SNF chromatin remodeler BRG1 $(110,112)$. Drosophila UTX is involved in similar protein interactions as its mammalian counterpart including direct binding to the BRG1 homolog nucleosome remodeler BRM (113) and being a subunit of the TRR containing COMPASS-like H3K4 methyltransferase complex (33). These conserved interactions suggest that demethylation independent activities of Drosophila Utx might be also conserved. Thus, while transcriptional dysregulation is strongly correlated with HD and other neurodegenerative diseases and attention has focused on histone modifications, many of the enzymes that regulate these processes have non-histone targets and at least some of them also have additional catalytic activities that may contribute to the disease process. Similar to our previous study that pointed to HDAC1 and SirT1 and SirT2 (114), this study points to the PRC2 component modifying enzyme, Utx, as the most attractive therapeutic target among the Drosophila methyl modifying enzymes.

\section{Materials and Methods}

\section{Drosophila crosses}

Flies were reared on standard cornmeal molasses medium at $25^{\circ} \mathrm{C}$ unless noted otherwise. Genetic interaction crosses were done by first mating elav-GAL4; Sp/CyO; $+/+$ (in case of second chromosomal mutation) or elav-GAL4; +/+; Sb/TM6 (in case of third chromosomal mutation) females with males carrying the mutation or RNAi construct of interest; then crossing the elavGAL4; mutation/Sp; +/+ or elav-GAL4; +/+; mutation/Sb F1 male progeny to $w ;+/+$; UAS-Httex1p-Q93 females. All F2 females express the UAS-Httex1p-Q93 transgene under the control of the neuronal elav-GAL4 driver; half of these females carry the mutation of interest in a heterozygous form, in F2 males elav-GAL4 is absent therefore they do not express UAS-Httex1p-Q93. To test mutations located on the first chromosome, we set up control crosses with $w^{1118}$ side by side with the experimental crosses in order to compare the viability and pseudopupil phenotypes between the mutation-carrying and control flies. Relative eclosion rates from $\geq 1000$ segregants were calculated as the ratio of the number of Httex1p-Q93 expressing flies carrying the mutation of interest (elav-GAL4/+; Htt/+; mutation/+) and the number of Httex1p-Q93 expressing mutation-free control flies (elav-GAL4/+; Htt/+; +/+) divided by the ratio of the number of Htt non-expressing siblings carrying the mutation of interest ( $+/ \mathrm{Y} ; \mathrm{Htt} /+$; mutation/ +$)$ and the number of Htt nonexpressing mutation-free siblings ( $/ \mathrm{Y} ; \mathrm{Htt} /+;+/+)$. P values were based on Fisher's exact tests. 


\section{Pseudopupil analysis}

The insect compound eye is comprised of 1000 ommatidia (individual eyes) each of which contains seven visible photoreceptor neurons that can be visualized by the specialized light gathering cellular structure called a rhabdomere. Pseudopupil analysis allows one to count the number of surviving photoreceptor neurons by counting the light gathering rhabdomeres. Analyses were carried out on 7 day old flies, which were raised $22.5^{\circ} \mathrm{C}$ and shifted to $25^{\circ} \mathrm{C}$ upon eclosion as described in detail (115). Change of rhabdomeres in each ommatidium was calculated as the difference of the number of rhabdomeres between the Httex1p-Q93 expressing flies with or without the heterozygous mutation of interest and the error bars represent the standard error of the mean (SEM) of difference of means. Pseudopupils of $\geq 5$ flies were scored for each genotype.

\section{Drug test}

Crosses of elav-GAL4 (females) x Httex1p-Q93 (males) were carried out in cages at $23^{\circ} \mathrm{C}$. About $60-100$ eggs collected overnight were transferred to vials of standard cornmeal molasses medium containing indicated concentrations of GSK-J4 as described (90) (Tocris Bioscience), 0.1\% DMSO (Sigma-Aldrich, negative control) or $100 \mathrm{mM} \mathrm{BA}$ (Sigma-Aldrich, positive control). Freshly eclosed virgin females were collected and passed in vials with the corresponding drug/control food every day and aged at $25^{\circ} \mathrm{C}$ for 7 days for pseudopupil analysis as described in (115).

\section{Generation of His3.3A transgenic flies}

Genomic DNA was first prepared from wild-type flies with NucleoSpin Tissue kit (Macherey-Nagel) and the genomic region of His3.3A was amplified by PCR using Q5 high-fidelity DNA polymerase (New England Biolabs) with primers located upstream (His3.3A_gF) or downstream (His3.3A_gR) of the gene. The 2174 bp amplicon was inserted to pJET1.2 vector with CloneJET PCR cloning kit (Thermo Scientific). This clone was used as template in PCR to amplify His3.3A from the start codon to the last codon before the stop codon using His3.3A_E3C_F (having a KpnI site and an AAA Kozak sequence before the start codon) and His3.3A_E3C_R primers (having an EcoRI site). The resulting amplicon was cut with FastDigest KpnI and EcoRI enzymes (Thermo Scientific) and cloned to the corresponding sites of pENTRY3C Gateway entry vector. Site directed mutagenesis was performed by amplifying the whole pENTRY3C-His3.3A clone in a 22 cycle inverse PCR reaction with Q5 polymerase using a common forward primer (K27_F, see Supplementary Material, Table S1 for all the primer sequences used in the study) and reverse primers having base substitutions at the desired positions (K27M_R and K27R_R). After PCR amplicons were phosphorylated with $\mathrm{T} 4$ polynucleotide kinase (Thermo Scientific), circularized with T4 DNA ligase (Thermo Scientific), and treated with DpnI to degrade methylated template DNA. Modified and wildtype H3.3A inserts were subcloned to PTWF-attB Gateway destination vector that was modified to carry a $\phi C 31$ attB sequence at its NsiI restriction site, then these constructs were injected to embryos carrying the attP-zh86Fb $\phi \mathrm{C} 31$ docking site to generate transgenic flies by site-specific transgene integration. To validate transgenic strains genomic DNA was prepared from transgenic flies, transgene sequences were PCR amplified using pTWFattB_Fseq and pTWFattB_Rseq primers, and subjected to Sanger sequencing.

\section{Longevity and motor performance of His3.3 mutants}

The effect of His3.3A point mutants on longevity and motor performance in the HD model was tested on elav-GAL4; His $3.3 \mathrm{~A}^{\mathrm{KO}}$ UAS-Httex1p-Q120/His3.3A ${ }^{\text {KO}}$; UAS-His3.3A/tub-GAL80 ${ }^{\text {ts }}$ flies, in which the UAS-His3.3A transgene was either wild-type (UASHis3.3A-wt), or had a lysine to arginine (UAS-His3.3A-K27R) or lysine to methionine (UAS-His3.3A-K27M) substitution. These progeny were generated by mating elav-GAL4; His3.3 $\mathrm{A}^{\mathrm{KO}}$; tub${\text { GAL } 80^{\text {ts }}}$ females to w; H3.3A ${ }^{\text {KO }}$ UAS-Httex1p-Q120; UAS-H3.3A males, raised at $18^{\circ} \mathrm{C}$ and transferred to $30^{\circ} \mathrm{C}$ after eclosion to induce transgene expression in the adult nervous system. To determine longevity, flies were kept at $30^{\circ} \mathrm{C}$, transferred to fresh vials every second day and the number of deceased individuals recorded daily. At least 185 flies per genotype were used for longevity analysis.

Climbing assays on elav-GAL4/+; His3.3A ${ }^{\text {KO }}$ UAS-Httex1pQ120/His3.3A ${ }^{\text {KO }}$; UAS-His3.3A/tub-GAL80 ${ }^{\text {ts }}$ flies were performed on males that were reared at $18^{\circ} \mathrm{C}$ and transferred to $30^{\circ} \mathrm{C}$ after eclosion. Groups of 10 days old flies were transferred to a glass cylinder and the distance climbed vertically in $10 \mathrm{~s}$ after knocked to the bottom was recorded on video for 8 trials per each group. At least 35 flies divided to several groups were tested for each genotype.

\section{Quantitative RT-PCR}

Heads of elav-GAL4 > UAS-Httex1p-Q93 with or without mutation (control) female flies were homogenized in TRIzol reagent (Invitrogen) and RNA was prepared according to the manufacturers' recommendations. First strand cDNA was prepared from $1 \mu \mathrm{g}$ of total RNA with Maxima Universal First Strand cDNA Synthesis Kit (Thermo Scientific) using random hexamer primers. The resulting cDNA was diluted 1:10 and quantified in $\mathrm{qPCR}$ reactions with gene-specific primers (UAS-F and UAS-R for Htt, G9a-F and G9a-R for G9a, Utx-F and Utx-R for Utx) in an MJ Research Opticon thermal cycler using SYBR Green PCR Master Mix (Applied Biosystems). Transgene expression levels were determined compared to a template calibration curve and normalized to that of the rp49 housekeeping gene.

\section{Immunostaining}

Wandering third instar larvae reared at $25^{\circ} \mathrm{C}$ were cut into half in a drop of $1 \times$ PBS and flipped inside out. After removing extra fat bodies and other tissues, the dissected larvae were incubated in fixative (4\% paraformaldehyde and $0.2 \%$ triton $\mathrm{X}-100$ in $1 \times$ PBS) for $20 \mathrm{~min}$. The larvae were then washed and blocked with PBSTS (10\% Bovine serum albumin in PBT) for $1 \mathrm{~h}$ at RT. After that, the larvae were incubated in rabbit polyclonal HTT exon1-specific antibody (1:2000 VB3130, Viva Bioscience) overnight at $4{ }^{\circ} \mathrm{C}$. Upon removal of the primary antibody, the larvae were blocked again with PBSTS for $1 \mathrm{~h}$ and incubated with secondary antibody solution (1:10 000 Alexa 568) for $1.5 \mathrm{~h}$ at RT. Finally, the eye discs were dissected and mounted in Vectashield antifade mounting medium (Vector Laboratories). Images were captured with a Zeiss 780 laser scanning confocal microscope (Carl Zeiss MicroImaging), using the accompanying Zeiss software. HTT aggregate-positive puncta were counted using the '3D Object Counter' plug-in in Image on maximumintensity compiled 3D images. The threshold levels were set to 1800 where most of the aggregates can be clearly identified. 


\section{Histone extraction and quantitative Western analysis}

For histone extraction, 3 day old female or male fly heads or L2 larvae were homogenized in 5\% Triton buffer (1× PBS, 5\% Triton $\mathrm{X}-100,3 \mathrm{mM}$ DTT, $1 \mathrm{mM}$ sodium orthovanadate, $5 \mathrm{mM}$ sodium fluoride, $1 \mathrm{mM}$ PMSF, $5 \mathrm{mM}$ sodium BA and 1 tablet of Roche's Complete Mini Protease Inhibitor), spun down at $4000 \mathrm{~g}$ for 8 min at $4{ }^{\circ} \mathrm{C}$ and the pellets containing the nuclei were washed $2 \times$ times with the same buffer. The pellets were then resuspended in $0.2 \mathrm{~N} \mathrm{HCl}$ and sonicated for two times of $10 \mathrm{~s}$ with $1 \mathrm{~min}$ interval at $4{ }^{\circ} \mathrm{C}$. The nuclear histone proteins were acid extracted for $3 \mathrm{~h}$ at $4{ }^{\circ} \mathrm{C}$. After centrifugation, the supernatant was neutralized and $2 \%$ deoxycholate was added to the final concentration of $125-250 \mu \mathrm{g} / \mathrm{ml}$ and the samples were incubated for $10 \mathrm{~min}$ at RT. Trichloroacetic acid was then added to a final concentration of $6 \%$ and the protein pellets were washed with cold acetone. The pellets were finally dried and dissolved in appropriate volume of $1 \mathrm{X}$ loading buffer (50 mM Tris, pH6.8, 2\% SDS, $10 \%$ glycerol, $0.0015 \%$ Bromophenol Blue). The samples were boiled for $5 \mathrm{~min}$ at $95{ }^{\circ} \mathrm{C}$ and loaded to custom-made $15 \%$ Tris-Tricine polyacrylamide gel and run at a constant voltage of $120 \mathrm{~V}$ for about $1 \mathrm{~h}$ until the dye reached the bottom of the gel. PVDF membrane was used for standard western blotting.

For quantitative western analysis, blots were blocked for 1 hour at room temperature using 50\% 1× PBS diluted Odyssey infrared imaging system blocking buffer (LiCor) and then incubated overnight at $4{ }^{\circ} \mathrm{C}$ with antibody against histone H3K27me3 (Active Motif no. 39155, 1:1000). Following incubation with primary antibody, blots were washed and incubated with goat anti-rabbit IRDYE 680CW (Li-Cor) secondary antibody (1:20 000) for $1 \mathrm{~h}$ at room temperature. Blots were washed and scanned using the Odyssey Infrared Imager (Li-Cor). After scanning, blots were incubated with the second primary antibody H2B (Active Motif no. 61037, 1:2000) overnight at $4^{\circ} \mathrm{C}$, then washed and incubated with goat anti-mouse IRDYE 800CW (Li-Cor) secondary anti-bodies (1:20 000), washed and scanned as above. Integrated signal intensity for histone modifications and total H2B was acquired using Odyssey Software. Data were exported to Excel and the ratios of signals from different histone modifications to total H2B obtained.

\section{Chromatin immunoprecipitation}

Chromatin samples from heads of 3 days old $w$ elav-GAL4/w; Httex1p-Q93/+ and $w$ elav-GAL4/w; Httex1p-Q20/+ females were prepared as described previously (116) with modifications. In short, 1500-2500 fly heads were ground under liquid $\mathrm{N}_{2}$ and homogenized in homogenization buffer (15 mM HEPES pH 7.6, $10 \mathrm{mM} \mathrm{KCl}, 5 \mathrm{mM} \mathrm{MgCl}_{2}$, $0.5 \mathrm{mM}$ EGTA, $0.1 \mathrm{mM}$ EDTA, $0.1 \%$ Tween, $350 \mathrm{mM}$ sucrose, with $1 \mathrm{mM}$ DTT, $1 \mathrm{mM}$ PMSF and Protease Inhibitor Cocktail (Merck)). Chromatin was crosslinked with $1 \%$ formaldehyde for $10 \mathrm{~min}$ at RT, then after collection and lysis of nuclei fragmented by sonication with a Bioruptor (Diagenode). Samples containing equal amounts of DNA as measured by a fluorometric method (Qubit 2.0 with BR DNA assay kit (Life Technologies)) were used for ChIP analysis. Diluted samples were pre-cleared with Dynabeads Protein A (Life Technologies) for $4 \mathrm{~h}$ at $4{ }^{\circ} \mathrm{C}$ and then immunoprecipitated with $3 \mu \mathrm{g}$ anti-H3 (Abcam ab1791) or anti-H3K27me3 (Millipore 07-449) ChIP-grade polyclonal antibody, or no antibody (mock control) at $4^{\circ} \mathrm{C}$ overnight. Chromatin-antibody complexes were bound to Dynabeads Protein A for $4 \mathrm{~h}$ at $4{ }^{\circ} \mathrm{C}$. The supernatant of the mock control was collected and used as total input control (TIC). After extensive washes chromatin was reverse crosslinked overnight at $65^{\circ} \mathrm{C}$, treated with RNase A and Proteinase $\mathrm{K}$, extracted with phenol-chloroform then precipitated with ethanol in the presence of glycogen. The amount of immunoprecipitated DNA was determined by quantitative PCR in a PikoReal Real-Time PCR system (Thermo Scientific) using Power SYBR Green Mastermix (Life Technologies). Gene-specific primers used are listed in Supplementary Material, Table S1. The quantity of immunoprecipitated DNA was determined by setting sample $\mathrm{Ct}$ values to a TIC calibration curve and deducting the amount of DNA in the mock controls.

\section{Supplementary Material}

Supplementary Material is available at HMG online.

\section{Acknowledgements}

The authors wish to thank Dr Jeff Simon for $E(z)^{63}$, Dr Andreas Bergmann for Utx alleles, Dr Alex Mazo for trr alleles, Dr Greg Shanower for gpp alleles and Dr Konrad Basler for the His3.3 $\mathrm{A}^{\mathrm{KO}}$ allele. We thank Dr Judit Pallos for her insight and help at the beginning of the project. We thank the Bloomington Drosophila Stock Center (NIH P40OD018537), the Drosophila Genomics Resource Center (DGRC), Bloomington, IN, supported by NIH grant (P40 OD010949) and the Vienna Drosophila Stock Center for providing fly stocks. The authors acknowledge the support of the Optical Biology Core facility and the Cancer Center Support grant of the University of California, Irvine (CC grant no. CA62203).

Conflict of Interest statement None declared.

\section{Funding}

This work was supported by the National Institutes of Health (NS045283 to J.L.M.); and Hungarian National Research, Development and Innovation Office (NKFIH) (K-112294, GINOP 2.3.2-15-2016-00034 to L.B.).

\section{References}

1. Macdonald, M.E., Ambrose, C.M., Duyao, M.P., Myers, R.H., Lin, C., Srinidhi, L., Barnes, G., Taylor, S.A., James, M. and Groot, N. (1993) A novel gene containing a trinucleotide repeat that is expanded and unstable on huntingtons-disease chromosomes. Cell, 72, 971-983.

2. Shirasaki, D.I., Greiner, E.R., Al-Ramahi, I., Gray, M., Boontheung, P., Geschwind, D.H., Botas, J., Coppola, G., Horvath, S. and Loo, J.A. (2012) Network organization of the huntingtin proteomic interactome in mammalian brain. Neuron, 75, 41-57.

3. McFarland, K.N., Das, S., Sun, T.T., Leyfer, D., Xia, E., Sangrey, G.R., Kuhn, A., Luthi-Carter, R., Clark, T.W., SadriVakili, G. et al. (2012) Genome-wide histone acetylation is altered in a transgenic mouse model of Huntington's disease. PLoS One, 7, e41423.

4. Ryu, H., Lee, J., Hagerty, S.W., Soh, B.Y., McAlpin, S.E., Cormier, K.A., Smith, K.M. and Ferrante, R.J. (2006) ESET/SETDB1 gene expression and histone H3 (K9) trimethylation in Huntington's disease. Proc. Natl. Acad. Sci. U. S. A., 103, 19176-19181.

5. Stack, E.C., Dedeoglu, A., Smith, K.M., Cormier, K., Kubilus, J.K., Bogdanov, M., Matson, W.R., Yang, L., Jenkins, B.G., Luthi-Carter, R. et al. (2007) Neuroprotective effects of 
synaptic modulation in Huntington's disease R6/2 mice. J. Neurosci., 27, 12908-12915.

6. Bai, G., Cheung, I., Shulha, H.P., Coelho, J.E., Li, P., Dong, X., Jakovcevski, M., Wang, Y., Grigorenko, A., Jiang, Y. et al. (2015) Epigenetic dysregulation of hairy and enhancer of split 4 (HES4) is associated with striatal degeneration in postmortem Huntington brains. Hum. Mol. Genet., 24, 1441-1456.

7. Vashishtha, M., Ng, C.W., Yildirim, F., Gipson, T.A., Kratter, I.H., Bodai, L., Song, W., Lau, A., Labadorf, A., Vogel-Ciernia, A. et al. (2013) Targeting H3K4 trimethylation in Huntington disease. Proc. Natl. Acad. Sci. U. S. A., 110, E3027-E3036.

8. Gardian, G., Browne, S.E., Choi, D.K., Klivenyi, P., Gregorio, J., Kubilus, J.K., Ryu, H., Langley, B., Ratan, R.R., Ferrante, R.J. et al. (2005) Neuroprotective effects of phenylbutyrate in the N171-82Q transgenic mouse model of Huntington's disease. J. Biol. Chem., 280, 556-563.

9. Spange, S., Wagner, T., Heinzel, T. and Kramer, O.H. (2009) Acetylation of non-histone proteins modulates cellular signalling at multiple levels. Int. J. Biochem. Cell Biol., 41, 185-198.

10. Biggar, K.K. and Li, S.S. (2015) Non-histone protein methylation as a regulator of cellular signalling and function. Nat. Rev. Mol. Cell Biol., 16, 5-17.

11. Gu, W. and Roeder, R.G. (1997) Activation of p53 sequence-specific DNA binding by acetylation of the p53 C-terminal domain. Cell, 90, 595-606.

12. Chuikov, S., Kurash, J.K., Wilson, J.R., Xiao, B., Justin, N., Ivanov, G.S., McKinney, K., Tempst, P., Prives, C., Gamblin, S.J. et al. (2004) Regulation of p53 activity through lysine methylation. Nature, 432, 353-360.

13. Jansson, M., Durant, S.T., Cho, E.C., Sheahan, S., Edelmann, M., Kessler, B. and La Thangue, N.B. (2008) Arginine methylation regulates the p53 response. Nat. Cell Biol, 10, 1431-1439.

14. Shi, X., Kachirskaia, I., Yamaguchi, H., West, L.E., Wen, H., Wang, E.W., Dutta, S., Appella, E. and Gozani, O. (2007) Modulation of $\mathrm{p} 53$ function by SET8-mediated methylation at lysine 382. Mol. Cell, 27, 636-646.

15. Nishioka, K., Chuikov, S., Sarma, K., Erdjument-Bromage, H., Allis, C.D., Tempst, P. and Reinberg, D. (2002) Set9, a novel histone $\mathrm{H} 3$ methyltransferase that facilitates transcription by precluding histone tail modifications required for heterochromatin formation. Genes Dev., 16, 479-489.

16. Sautel, C.F., Cannella, D., Bastien, O., Kieffer, S., Aldebert, D., Garin, J., Tardieux, I., Belrhali, H. and Hakimi, M.A. (2007) SET8-mediated methylations of histone H4 lysine 20 mark silent heterochromatic domains in apicomplexan genomes. Mol. Cell. Biol., 27, 5711-5724.

17. Tse, C., Sera, T., Wolffe, A.P. and Hansen, J.C. (1998) Disruption of higher-order folding by core histone acetylation dramatically enhances transcription of nucleosomal arrays by RNA polymerase III. Mol. Cell. Biol., 18, 4629-4638.

18. Cosgrove, M.S., Boeke, J.D. and Wolberger, C. (2004) Regulated nucleosome mobility and the histone code. Nat. Struct. Mol. Biol., 11, 1037-1043.

19. Ruthenburg, A.J., Li, H., Patel, D.J. and Allis, C.D. (2007) Multivalent engagement of chromatin modifications by linked binding modules. Nat. Rev. Mol. Cell Biol., 8, 983-994.

20. Martin, C. and Zhang, Y. (2005) The diverse functions of histone lysine methylation. Nat. Rev. Mol. Cell Biol., 6, 838-849.

21. Cloos, P.A.C., Christensen, J., Agger, K., Maiolica, A., Rappsilber, J., Antal, T., Hansen, K.H. and Helin, K. (2006) The putative oncogene GASC1 demethylates tri- and dimethylated lysine 9 on histone H3. Nature, 442, 307-311.
22. Klose, R.J., Kallin, E.M. and Zhang, Y. (2006) JmjC-domain-containing proteins and histone demethylation. Nat. Rev. Genet., 7, 715-727.

23. Li, B., Carey, M. and Workman, J.L. (2007) The role of chromatin during transcription. Cell, 128, 707-719.

24. Steger, D.J., Lefterova, M.I., Ying, L., Stonestrom, A.J., Schupp, M., Zhuo, D., Vakoc, A.L., Kim, J.E., Chen, J., Lazar, M.A. et al. (2008) DOT1L/KMT4 recruitment and H3K79 methylation are ubiquitously coupled with gene transcription in mammalian cells. Mol. Cell. Biol., 28, 2825-2839.

25. Kouzarides, T. (2007) Chromatin modifications and their function. Cell, 128, 693-705.

26. Kharchenko, P.V., Alekseyenko, A.A., Schwartz, Y.B., Minoda, A., Riddle, N.C., Ernst, J., Sabo, P.J., Larschan, E., Gorchakov, A.A., Gu, T. et al. (2011) Comprehensive analysis of the chromatin landscape in Drosophila melanogaster. Nature, 471, 480-485.

27. Noma, K., Allis, C.D. and Grewal, S.I.S. (2001) Transitions in distinct histone $\mathrm{H} 3$ methylation patterns at the heterochromatin domain boundaries. Science, 293, 1150-1155.

28. Santos-Rosa, H., Schneider, R., Bannister, A.J., Sherriff, J., Bernstein, B.E., Emre, N.C.T., Schreiber, S.L., Mellor, J. and Kouzarides, T. (2002) Active genes are tri-methylated at K4 of histone H3. Nature, 419, 407-411.

29. Liang, G., Lin, J.C., Wei, V., Yoo, C., Cheng, J.C., Nguyen, C.T., Weisenberger, D.J., Egger, G., Takai, D., Gonzales, F.A. et al. (2004) Distinct localization of histone H3 acetylation and H3-K4 methylation to the transcription start sites in the human genome. Proc. Natl. Acad. Sci. U. S. A., 101, 7357-7362.

30. Schneider, R., Bannister, A.J., Myers, F.A., Thorne, A.W., Crane-Robinson, C. and Kouzarides, T. (2004) Histone H3 lysine 4 methylation patterns in higher eukaryotic genes. Nat. Cell Biol., 6, 73-77.

31. Bernstein, B.E., Kamal, M., Lindblad-Toh, K., Bekiranov, S., Bailey, D.K., Huebert, D.J., McMahon, S., Karlsson, E.K., Kulbokas, E.J., 3rd, Gingeras, T.R. et al. (2005) Genomic maps and comparative analysis of histone modifications in human and mouse. Cell, 120, 169-181.

32. Joshi, A.A. and Struhl, K. (2005) Eaf3 chromodomain interaction with methylated H3-K36 links histone deacetylation to Pol II elongation. Mol. Cell, 20, 971-978.

33. Mohan, M., Herz, H.M., Smith, E.R., Zhang, Y., Jackson, J., Washburn, M.P., Florens, L., Eissenberg, J.C. and Shilatifard, A. (2011) The COMPASS family of H3K4 methylases in Drosophila. Mol. Cell. Biol., 31, 4310-4318.

34. Hallson, G., Hollebakken, R.E., Li, T.S., Syrzycka, M., Kim, I., Cotsworth, S., Fitzpatrick, K.A., Sinclair, D.A.R. and Honda, B.M. (2012) dSet1 is the main H3K4 di- and tri-methyltransferase throughout Drosophila development. Genetics, 190, 91-U516.

35. Steffan, J.S., Bodai, L., Pallos, J., Poelman, M., McCampbell, A., Apostol, B.L., Kazantsev, A., Schmidt, E., Zhu, Y.Z., Greenwald, M. et al. (2001) Histone deacetylase inhibitors arrest polyglutamine-dependent neurodegeneration in Drosophila. Nature, 413, 739-743.

36. Breen, T.R. and Harte, P.J. (1991) Molecular characterization of the trithorax gene, a positive regulator of homeotic gene-expression in Drosophila. Mech. Dev., 35, 113-127.

37. Sedkov, Y., Benes, J.J., Berger, J.R., Riker, K.M., Tillib, S., Jones, R.S. and Mazo, A. (1999) Molecular genetic analysis of the Drosophila trithorax-related gene which encodes a novel SET domain protein. Mech. Dev., 82, 171-179.

38. Sedkov, Y., Cho, E., Petruk, S., Cherbas, L., Smith, S.T., Jones, R.S., Cherbas, P., Canaani, E., Jaynes, J.B. and Mazo, A. (2003) 
Methylation at lysine 4 of histone $\mathrm{H} 3$ in ecdysone-dependent development of Drosophila. Nature, 426, 78-83.

39. Di Stefano, L., Ji, J.Y., Moon, N.S., Herr, A. and Dyson, N. (2007) Mutation of Drosophila Lsd1 disrupts H3-K4 methylation, resulting in tissue-specific defects during development. Curr. Biol., 17, 808-812.

40. Rudolph, T., Yonezawa, M., Lein, S., Heidrich, K., Kubicek, S., Schafer, C., Phalke, S., Walther, M., Schmidt, A., Jenuwein, T. et al. (2007) Heterochromatin formation in Drosophila is initiated through active removal of H3K4 methylation by the LSD1 homolog SU(VAR)3-3. Mol. Cell, 26, 103-115.

41. Eissenberg, J.C., Lee, M.G., Schneider, J., Ilvarsonn, A., Shiekhattar, R. and Shilatifard, A. (2007) The trithorax-group gene in Drosophila little imaginal discs encodes a trimethylated histone H3 Lys4 demethylase. Nat. Struct. Mol. Biol., 14, 344-346.

42. Lee, N., Zhang, J.Y., Klose, R.J., Erdjument-Bromage, H., Tempst, P., Jones, R.S. and Zhang, Y. (2007) The trithorax-group protein Lid is a histone H3 trimethyl-Lys4 demethylase. Nat. Struct. Mol. Biol., 14, 341-343.

43. Lloret-Llinares, M., Carre, C., Vaquero, A., de Olano, N. and Azorin, F. (2008) Characterization of Drosophila melanogaster JmjC $+\mathrm{N}$ histone demethylases. Nucleic Acids Res., $36,2852-2863$.

44. Kavi, H.H. and Birchler, J.A. (2009) Drosophila KDM2 is a H3K4me3 demethylase regulating nucleolar organization. BMC Res. Notes, 2, 217.

45. Li, L., Greer, C., Eisenman, R.N. and Secombe, J. (2010) Essential functions of the histone demethylase lid. PLoS Genet., 6, e1001221.

46. Tanaka, Y., Katagiri, Z., Kawahashi, K., Kioussis, D. and Kitajima, S. (2007) Trithorax-group protein ASH1 methylates histone $\mathrm{H} 3$ lysine 36 . Gene, 397, 161-168.

47. Bell, O., Wirbelauer, C., Hild, M., Scharf, A.N., Schwaiger, M., MacAlpine, D.M., Zilbermann, F., van Leeuwen, F., Bell, S.P., Imhof, A. et al. (2007) Localized H3K36 methylation states define histone H4K16 acetylation during transcriptional elongation in Drosophila. embo J., 26, 4974-4984.

48. Stabell, M., Larsson, J., Aalen, R.B. and Lambertsson, A. (2007) Drosophila dSet2 functions in H3-K36 methylation and is required for development. Biochem. Biophys. Res. Commun., 359, 784-789.

49. Tripoulas, N.A., Hersperger, E., La Jeunesse, D. and Shearn, A. (1994) Molecular-genetic analysis of the drosophila-melanogaster gene absent, small or homeotic discs1 (Ash1). Genetics, 137, 1027-1038.

50. Beisel, C., Imhof, A., Greene, J., Kremmer, E. and Sauer, F. (2002) Histone methylation by the Drosophila epigenetic transcriptional regulator Ash1. Nature, 419, 857-862.

51. Yuan, W., Xu, M., Huang, C., Liu, N., Chen, S. and Zhu, B. (2011) H3K36 Methylation Antagonizes PRC2-mediated H3K27 Methylation. J. Biol. Chem., 286, 7983-7989.

52. Dorighi, K.M. and Tamkun, J.W. (2013) The trithorax group proteins Kismet and ASH1 promote H3K36 dimethylation to counteract Polycomb group repression in Drosophila. Development, 140, 4182-4192.

53. Tripoulas, N., LaJeunesse, D., Gildea, J. and Shearn, A. (1996) The Drosophila ash1 gene product, which is localized at specific sites on polytene chromosomes, contains a SET domain and a PHD finger. Genetics, 143, 913-928.

54. Whetstine, J.R., Nottke, A., Lan, F., Huarte, M., Smolikov, S., Chen, Z., Spooner, E., Li, E., Zhang, G., Colaiacovo, M. and Shi, Y. (2006) Reversal of histone lysine trimethylation by the JMJD2 family of histone demethylases. Cell, 125, 467-481.

55. Lin, C.H., Li, B., Swanson, S., Zhang, Y., Florens, L., Washburn, M.P., Abmayr, S.M. and Workman, J.L. (2008) Heterochromatin protein 1a stimulates histone H3 lysine 36 demethylation by the Drosophila KDM4A demethylase. Mol. Cell, 32, 696-706.

56. Shanower, G.A., Muller, M., Blanton, J.L., Honti, V., Gyurkovics, H. and Schedl, P. (2005) Characterization of the grappa gene, the Drosophila histone H3 lysine 79 methyltransferase. Genetics, 169, 173-184.

57. Frederiks, F., Tzouros, M., Oudgenoeg, G., van Welsem, T., Fornerod, M., Krijgsveld, J. and van Leeuwen, F. (2008) Nonprocessive methylation by Dot1 leads to functional redundancy of histone H3K79 methylation states. Nat. Struct. Mol. Biol., 15, 550-557.

58. Hall, I.M., Shankaranarayana, G.D., Noma, K.I., Ayoub, N., Cohen, A. and Grewal, S.I.S. (2002) Establishment and maintenance of a heterochromatin domain. Science, 297, 2232-2237.

59. Nielsen, A.L., Sanchez, C., Ichinose, H., Cervino, M., Lerouge, T., Chambon, P. and Losson, R. (2002) Selective interaction between the chromatin-remodeling factor BRG1 and the heterochromatin-associated protein HP1 alpha. embo J., 21, 5797-5806.

60. Peters, A.H.F.M., Mermoud, J.E., O'Carroll, D., Pagani, M., Schweizer, D., Brockdorff, N. and Jenuwein, T. (2002) Histone H3 lysine 9 methylation is an epigenetic imprint of facultative heterochromatin. Nat. Genet., 30, 77-80.

61. Schultz, D.C., Ayyanathan, K., Negorev, D., Maul, G.G. and Rauscher, F.J. 3rd. (2002) SETDB1: a novel KAP-1-associated histone $\mathrm{H} 3$, lysine 9-specific methyltransferase that contributes to HP1-mediated silencing of euchromatic genes by KRAB zinc-finger proteins. Genes Deu., 16, 919-932.

62. Blackburn, M.L., Chansky, H.A., Zielinska-Kwiatkowska, A., Matsui, Y. and Yang, L. (2003) Genomic structure and expression of the mouse ESET gene encoding an ERG-associated histone methyltransferase with a SET domain. Biochim. Biophys. Acta, 1629, 8-14.

63. Stabell, M., Bjorkmo, M., Aalen, R.B. and Lambertsson, A. (2006) The Drosophila SET domain encoding gene dEset is essential for proper development. Hereditas, 143, 177-188.

64. Schotta, G., Ebert, A. and Reuter, G. (2003) SU(VAR)3-9 is a conserved key function in heterochromatic gene silencing. Genetica, 117, 149-158.

65. Tachibana, M., Sugimoto, K., Fukushima, T. and Shinkai, Y. (2001) SET domain-containing protein, G9a, is a novel lysine-preferring mammalian histone methyltransferase with hyperactivity and specific selectivity to lysines 9 and 27 of histone H3. J. Biol. Chem., 276, 25309-25317.

66. Stabell, M., Eskeland, R., Bjorkmo, M., Larsson, J., Aalen, R.B., Imhof, A. and Lambertsson, A. (2006) The Drosophila G9a gene encodes a multi-catalytic histone methyltransferase required for normal development. Nucleic Acids Res., 34, 4609-4621.

67. Brower-Toland, B., Riddle, N.C., Jiang, H.M., Huisinga, K.L. and Elgin, S.C.R. (2009) Multiple SET methyltransferases are required to maintain normal heterochromatin domains in the genome of Drosophila melanogaster. Genetics, 181, 1303-1319.

68. Clough, E., Moon, W., Wang, S.X., Smith, K. and Hazelrigg, T. (2007) Histone methylation is required for oogenesis in Drosophila. Development, 134, 157-165. 
69. Ebert, A., Schotta, G., Lein, S., Kubicek, S., Krauss, V., Jenuwein, T. and Reuter, G. (2004) Su(var) genes regulate the balance between euchromatin and heterochromatin in Drosophila. Genes Dev., 18, 2973-2983.

70. Reuter, D., Kuhnlein, R.P., Frommer, G., Barrio, R., Kafatos, F.C., Jackle, H. and Schuh, R. (1996) Regulation, function and potential origin of the Drosophila gene spalt adjacent, which encodes a secreted protein expressed in the early embryo. Chromosoma, 104, 445-454.

71. Yamane, K., Toumazou, C., Tsukada, Y., ErdjumentBromage, H., Tempst, P., Wong, J.M. and Zhang, Y. (2006) JHDM2A, a JmjC-containing H3K9 dernethylase, facilitates transcription activation by androgen receptor. Cell, 125, 483-495.

72. Klose, R.J., Yamane, K., Bae, Y.J., Zhang, D.Z., ErdjumentBromage, H., Tempst, P., Wong, J.M. and Zhang, Y. (2006) The transcriptional repressor JHDM3A demethylates trimethyl histone H3 lysine 9 and lysine 36. Nature, 442, 312-316.

73. Palomera-Sanchez, Z., Bucio-Mendez, A., Valadez-Graham, V., Reynaud, E. and Zurita, M. (2010) Drosophila p53 is required to increase the levels of the dKDM4B demethylase after UV-induced DNA damage to demethylate histone H3 lysine 9. J. Biol. Chem., 285, 31370-31379.

74. Jorgensen, S., Schotta, G. and Sorensen, C.S. (2013) Histone H4 Lysine 20 methylation: key player in epigenetic regulation of genomic integrity. Nucleic Acids Res., 41, 2797-2806.

75. Couture, J.F., Collazo, E., Brunzelle, J.S. and Trievel, R.C. (2005) Structural and functional analysis of SET8, a histone H4 Lys-20 methyltransferase. Genes Dev., 19, 1455-1465.

76. Karachentsev, D., Sarma, K., Reinberg, D. and Steward, R. (2005) PR-Set7-dependent methylation of histone H4 Lys 20 functions in repression of gene expression and is essential for mitosis. Genes Dev., 19, 431-435.

77. Sakaguchi, A., Karachentsev, D., Seth-Pasricha, M., Druzhinina, M. and Steward, R. (2008) Functional characterization of the Drosophila Hmt4-20/Suv4-20 histone methyltransferase. Genetics, 179, 317-322.

78. Fang, J., Feng, Q., Ketel, C.S., Wang, H.B., Cao, R., Xia, L., Erdjument-Bromage, H., Tempst, P., Simon, J.A. and Zhang, Y. (2002) Purification and functional characterization of SET8, a nucleosomal histone H4-lysine 20-specific methyltransferase. Curr. Biol., 12, 1086-1099.

79. Kuzmichev, A., Nishioka, K., Erdjument-Bromage, H., Tempst, P. and Reinberg, D. (2002) Histone methyltransferase activity associated with a human multiprotein complex containing the Enhancer of Zeste protein. Genes Deu., 16, 2893-2905.

80. Seong, I.S., Woda, J.M., Song, J.-J., Lloret, A., Abeyrathne, P.D., Woo, C.J., Gregory, G., Lee, J.-M., Wheeler, V.C., Walz, T. et al. (2010) Huntingtin facilitates polycomb repressive complex 2. Hum. Mol. Genet., 19, 573-583.

81. Czermin, B., Melfi, R., McCabe, D., Seitz, V., Imhof, A. and Pirrotta, V. (2002) Drosophila enhancer of Zeste/ESC complexes have a histone $\mathrm{H} 3$ methyltransferase activity that marks chromosomal polycomb sites. Cell, 111, 185-196.

82. Muller, J., Hart, C.M., Francis, N.J., Vargas, M.L., Sengupta, A., Wild, B., Miller, E.L., O'Connor, M.B., Kingston, R.E. and Simon, J.A. (2002) Histone methyltransferase activity of a Drosophila Polycomb group repressor complex. Cell, 111, 197-208.

83. Cao, R., Wang, L., Wang, H., Xia, L., Erdjument-Bromage, H., Tempst, P., Jones, R.S. and Zhang, Y. (2002) Role of histone
H3 lysine 27 methylation in Polycomb-group silencing. Science (New York, N Y), 298, 1039-1043.

84. Smith, E.R., Lee, M.G., Winter, B., Droz, N.M., Eissenberg, J.C., Shiekhattar, R. and Shilatifard, A. (2008) Drosophila UTX is a histone H3 Lys27 demethylase that colocalizes with the elongating form of RNA polymerase II. Mol. Cell. Biol., 28, 1041-1046.

85. Ketel, C.S., Andersen, E.F., Vargas, M.L., Suh, J., Strome, S. and Simon, J.A. (2005) Subunit contributions to histone methyltransferase activities of fly and worm polycomb group complexes. Mol. Cell. Biol., 25, 6857-6868.

86. Cao, R. and Zhang, Y. (2004) SUZ12 is required for both the histone methyltransferase activity and the silencing function of the EED-EZH2 complex. Mol. Cell, 15, 57-67.

87. Montgomery, N.D., Yee, D., Chen, A., Kalantry, S., Chamberlain, S.J., Otte, A.P. and Magnuson, T. (2005) The murine polycomb group protein Eed is required for global histone H3 lysine-27 methylation. Curr. Biol., 15, 942-947.

88. Tavares, L., Dimitrova, E., Oxley, D., Webster, J., Poot, R., Demmers, J., Bezstarosti, K., Taylor, S., Ura, H., Koide, H. et al. (2012) RYBP-PRC1 complexes mediate H2A ubiquitylation at polycomb target sites independently of PRC2 and H3K27me3. Cell, 148, 664-678.

89. Herz, H.M., Madden, L.D., Chen, Z., Bolduc, C., Buff, E., Gupta, R., Davuluri, R., Shilatifard, A., Hariharan, I.K. and Bergmann, A. (2010) The H3K27me3 demethylase dUTX is a suppressor of Notch- and Rb-dependent tumors in Drosophila. Mol. Cell. Biol., 30, 2485-2497.

90. Kruidenier, L., Chung, C.W., Cheng, Z., Liddle, J., Che, K., Joberty, G., Bantscheff, M., Bountra, C., Bridges, A., Diallo, H. et al. (2012) A selective jumonji H3K27 demethylase inhibitor modulates the proinflammatory macrophage response. Nature, 488, 404-408.

91. Roy, S., Ernst, J., Kharchenko, P.V., Kheradpour, P., Negre, N., Eaton, M.L., Landolin, J.M., Bristow, C.A., Ma, L., Lin, M.F. et al. (2010) Identification of functional elements and regulatory circuits by Drosophila modENCODE. Science, 330, 1787-1797.

92. Graveley, B.R., Brooks, A.N., Carlson, J.W., Duff, M.O., Landolin, J.M., Yang, L., Artieri, C.G., van Baren, M.J., Boley, N., Booth, B.W. et al. (2011) The developmental transcriptome of Drosophila melanogaster. Nature, 471, 473-479.

93. Ahmad, K. and Henikoff, S. (2002) The histone variant H3.3 marks active chromatin by replication-independent nucleosome assembly. Mol. Cell, 9, 1191-1200.

94. McKittrick, E., Gafken, P.R., Ahmad, K. and Henikoff, S. (2004) Histone H3.3 is enriched in covalent modifications associated with active chromatin. Proc. Natl. Acad. Sci. U. S. A., 101, 1525-1530.

95. Marsh, J.L. and Thompson, L.M. (2004) Can flies help humans treat neurodegenerative diseases? Bioessays, 26, 485-496.

96. Bachand, F. (2007) Protein arginine methyltransferases: from unicellular eukaryotes to humans. Eukaryot. Cell, 6, 889-898.

97. Ditzel, M., Broemer, M., Tenev, T., Bolduc, C., Lee, T.V., Rigbolt, K.T., Elliott, R., Zvelebil, M., Blagoev, B., Bergmann, A. et al. (2008) Inactivation of effector caspases through nondegradative polyubiquitylation. Mol. Cell, 32, 540-553.

98. Lee, Y.S., Pressman, S., Andress, A.P., Kim, K., White, J.L., Cassidy, J.J., Li, X., Lubell, K., Lim, D.H., Cho, I.S. et al. (2009) Silencing by small RNAs is linked to endosomal trafficking. Nat. Cell Biol., 11, 1150-1156. 
99. Luthi-Carter, R., Hanson, S.A., Strand, A.D., Bergstrom, D.A., Chun, W.J., Peters, N.L., Woods, A.M., Chan, E.Y., Kooperberg, C., Krainc, D. et al. (2002) Dysregulation of gene expression in the R6/2 model of polyglutamine disease: parallel changes in muscle and brain. Hum. Mol. Genet., 11, 1911-1926.

100. Luthi-Carter, R., Strand, A.D., Hanson, S.A., Kooperberg, C., Schilling, G., La Spada, A.R., Merry, D.E., Young, A.B., Ross, C.A., Borchelt, D.R. et al. (2002) Polyglutamine and transcription: gene expression changes shared by DRPLA and Huntington's disease mouse models reveal context-independent effects. Hum. Mol. Genet., 11, 1927-1937.

101. Robakis, N.K. (2003) An Alzheimer's disease hypothesis based on transcriptional dysregulation. Amyloid, 10, 80-85.

102. Yacoubian, T.A., Cantuti-Castelvetri, I., Bouzou, B., Asteris, G., McLean, P.J., Hyman, B.T. and Standaert, D.G. (2008) Transcriptional dysregulation in a transgenic model of Parkinson disease. Neurobiol. Dis., 29, 515-528.

103. Alarcon, J.M., Malleret, G., Touzani, K., Vronskaya, S., Ishii, S., Kandel, E.R. and Barco, A. (2004) Chromatin acetylation, memory, and LTP are impaired in CBP+/- mice: A model for the cognitive deficit in Rubinstein-Taybi syndrome and its amelioration. Neuron, 42, 947-959.

104. Dong, X., Tsuji, J., Labadorf, A., Roussos, P., Chen, J.F., Myers, R.H., Akbarian, S. and Weng, Z. (2015) The role of H3K4me3 in transcriptional regulation is altered in Huntington's disease. PLoS One, 10, e0144398.

105. von Schimmelmann, M., Feinberg, P.A., Sullivan, J.M., Ku, S.M., Badimon, A., Duff, M.K., Wang, Z., Lachmann, A., Dewell, S., Ma'ayan, A. et al. (2016) Polycomb repressive complex 2 (PRC2) silences genes responsible for neurodegeneration. Nat. Neurosci., 19, 1321-1330.

106. Li, J., Hart, R.P., Mallimo, E.M., Swerdel, M.R., Kusnecov, A.W. and Herrup, K. (2013) EZH2-mediated H3K27 trimethylation mediates neurodegeneration in ataxia-telangiectasia. Nat. Neurosci., 16, 1745-1753.

107. Woo, C.J., Maier, V.K., Davey, R., Brennan, J., Li, G., Brothers, J., 2nd, Schwartz, B., Gordo, S., Kasper, A., Okamoto, T.R. et al. (2017) Gene activation of SMN by selective disruption of lncRNA-mediated recruitment of PRC2 for the treatment of spinal muscular atrophy. Proc. Natl. Acad. Sci. U. S. A., 114, E1509-E1518.

108. Kim, E., Kim, M., Woo, D.H., Shin, Y., Shin, J., Chang, N., Oh, Y.T., Kim, H., Rheey, J., Nakano, I. et al. (2013) Phosphorylation of EZH2 activates STAT3 signaling via STAT3 methylation and promotes tumorigenicity of glioblastoma stem-like cells. Cancer Cell, 23, 839-852.

109. Vasanthakumar, A., Xu, D., Lun, A.T., Kueh, A.J., van Gisbergen, K.P., Iannarella, N., Li, X., Yu, L., Wang, D., Williams, B.R. et al. (2017) A non-canonical function of Ezh2 preserves immune homeostasis. EMBO Rep., 18, 619-631.

110. Shpargel, K.B., Sengoku, T., Yokoyama, S., Magnuson, T. and Wysocka, J. (2012) UTX and UTY demonstrate histone demethylase-independent function in mouse embryonic development. PLoS Genet., 8, e1002964.

111. Lee, S., Lee, J.W. and Lee, S.K. (2012) UTX, a histone H3-lysine 27 demethylase, acts as a critical switch to activate the cardiac developmental program. Dev. Cell, 22, 25-37.

112. Miller, S.A., Mohn, S.E. and Weinmann, A.S. (2010) Jmjd3 and UTX play a demethylase-independent role in chromatin remodeling to regulate $\mathrm{T}$-box family member-dependent gene expression. Mol. Cell, 40, 594-605.

113. Tie, F., Banerjee, R., Conrad, P.A., Scacheri, P.C. and Harte, P.J. (2012) Histone demethylase UTX and chromatin remodeler BRM bind directly to CBP and modulate acetylation of histone H3 lysine 27. Mol. Cell. Biol., 32, 2323-2334.

114. Pallos, J., Bodai, L., Lukacsovich, T., Purcell, J.M., Steffan, J.S., Thompson, L.M. and Marsh, J.L. (2008) Inhibition of specific HDACs and sirtuins suppresses pathogenesis in a Drosophila model of Huntington's disease. Hum. Mol. Genet., 17, 3767-3775.

115. Song, W., Smith, M.R., Syed, A., Lukacsovich, T., Barbaro, B.A., Purcell, J., Bornemann, D.J., Burke, J. and Marsh, J.L. (2013) Hatters, D.M. and Hannan, A.J. (eds.), In Tandem Repeats in Genes, Proteins, and Disease: Methods and Protocols, Springer Science+Business Media, New York, Vol. 1017, pp. 41-57.

116. Schauer, T., Schwalie, P.C., Handley, A., Margulies, C.E., Flicek, P. and Ladurner, A.G. (2013) CAST-ChIP maps cell-type-specific chromatin states in the Drosophila central nervous system. Cell Rep., 5, 271-282. 